\title{
Measuring the Maturity of Indian Small and Medium Enterprises for Unofficial Readiness for Capability Maturity Model Integration-based Software Process Improvement
}

\author{
Ashima Singh ${ }^{1}$ and Sukhpal Singh Gill ${ }^{2}$ \\ ${ }^{1}$ Computer Science and Engineering Department, Thapar Institute of Engineering \& Technology, Patiala, India \\ ${ }^{2}$ School of Electronic Engineering and Computer Science, Queen Mary University of London, UK \\ ashima@thapar.edu, s.s.gill@qmul.ac.uk
}

\begin{abstract}
Establishing the maturity levels of - Small and Medium Enterprises (SMEs) without Capability Maturity Model Integration (CMMI) certification has always been regarded as an extremely challenging task. Software process improvement (SPI) has targeted to monitor and improve software processes, thereby improving the software business. Although there is scientific interest in SPI, little attention has been specifically given to the exploration of maturity levels for non-CMMI SMEs. The goal is to explore the effect of time on process maturity and maturity levels achieved informally or unofficially by SMEs that are not otherwise CMMI certified. To find out the maturity levels achieved informally, a CMMI-DEV v1.3 based survey questionnaire is administered to Indian software SMEs. Time of establishment of SMEs and follow-up of CMMI-based processes and practices unofficially are used as two important parameters to decide upon process maturity and achievement of specific CMMI level informally. This paper has been successful in ascertaining the effect of time of establishment of SMEs and follow-up of CMMI-based processes on process maturity using proposed RuleML that advocates adoption of more than $70 \%$ of CMMI-DEV v1.3 process area-specific practices for an SME to be unofficially ready for CMMI-based SPI initiatives. The findings manifest multidimensional aspects of unofficial readiness of SMEs for CMMI-based SPI that can be used by relevant authorities to select SMEs for funding for SPI initiatives. Finally, the proposed work has been validated statistically using t-test for CMMI Level II and Level III.
\end{abstract}

Keywords: Capability Maturity Model Integration; Software Process Improvement; Small and Medium Enterprises; CMMI-DEVv1.3 Process Areas and Specific Practices.

\section{Introduction}

Various SPI models exist in software industry namely Capability Maturity Model (CMM), Capability Maturity Model Integration (CMMI), People Software Process (PSP), Software Process Improvement and Capability dEtermination (SPICE) and BOOTSTRAP (Berente \& Lee, 2014). Berente \& Lee (2014) explored and suggested that these models have been providing continuous improvement and an edge to sustainable software development. CMMI Model has been seen as a generic model suitable for various industries. Veldman and Klingenberg (2009) has established CMMI as the excellent process framework adopted by Software Enterprises (SEs) containing the best practices which can be referred by other companies. Beecham et al. (2008) explained software engineering as a challenging profession and therefore Software Process Improvement (SPI). Badoo et al. (2006) discussed adherence to good practices results in software project success in high maturity organizations. Zephir et al. (2011) working on the European project tried to evaluate the maturity of the enterprise by applying novel practices characterized as a change with respect to structure or technology. Niazi et al. (2008) have explored that even highly resourceful organizations are not able to achieve desired maturity levels and results. Al-Tarawneh et al. (2011) have discussed different stages of a framework for improving the process of software development in small Software Enterprises (SEs). Integration of SPI model as CMMI and method of development as Extreme Programming (XP) has been discussed as a novel approach for SPI. Team (2010) has emphasized that present century to be characterized by ahigh-technology environment where even SMEs want to rollout highly qualified products and services in short period of time. Hosalkar \& Bowonder (2000) has identified that usage of Software Quality Management (SQM) enabled SEs to reduce development time, speedy delivery of products with higher quality and satisfaction of market needs. Lester et al. (2010) have discussed appraisals of ten Small and Medium Enterprises (SMEs) practicing software development. It has been noticed by the researchers that software organizations started following a greater number of practices of CMMI as they have grown in size. Berente \& Lee (2014) have emphasized on technological innovation management to theorize and organize SPI efforts in organizations. The authors have formulated a set of four categories of propositions. The example of four categories are Direct, 
Resource Capacity, Knowledge, and Management Vision (Singh \& Singh, 2013). Wubben et al. (2015) have found innovation important for the growth of any organization. Singh \& Aggarwal (2017) ruled out numerous facilitating factors which could provide a fertile ground for software process reengineering in achieving CMMI levels.

\subsection{Motivation}

The main objective of the present work is to identify the trends of acceptance and adoption of well-known SPI standard i.e. CMMI Dev v1.3 informally by SMEs. Time specific investigation is carried out for the purpose as the attainment of CMMI levels consumed huge time which is indicated and reported by SEI (2006). The following research questions (RQs) have been framed to reach a conclusion.

$R Q-I$ : What is the difference between the maturity levels of Indian non-CMMI SMEs established for less than five years and non-CMMI SMEs established for more than five years?

RQ-II: Which CMMI maturity level can be given to Indian SMEs unofficially on the basis of informal adoption of CMMI Dev v1.3 Process Area-Specific practices?

This paper is motivated by a study carried out by Iqbal et al. (2016) who proposed to explore the unofficial readiness of software organizations towards CMMI. There are number of SMEs which are delivering great products developed using qualified processes. These SMEs are not certified by any external or international organizations like CMM or CMMI. The authors evaluated the unofficial readiness of such SMEs towards CMMI basing the study on the percentage of adoption of CMMI practices. This paper replicated the study carried out by Iqbal et al. (2016). We followed the methodology adopted by Iqbal et al. (2016) with a little variation in selecting ratings for percentages of follow-up of CMMI practices, for evaluating unofficial readiness of Indian SMEs towards CMMI. Indian SMES are performing well and are also contributing to Gross Domestic Product (GDP). This is the first paper which evaluates the CMMI Maturity of Indian Non-CMMI SMEs. The methodology is applied taking non-certified Indian software SMEs into consideration to find their maturity index according to CMMI practices on the basis of their time of establishment.

\subsection{Article Structure}

The rest of the paper is organized in six different sections. Section 2 discusses the significance, awareness, and evolution of CMMI as a staged and continuous model. Section 3 guide through the research methodology followed for the research work. Section 4 firstly elaborates upon the methodology applied to answer RQ-I and RQ-II. It rigorously compares and analyses Non-CMMI SMEs which are established within five years and Non-CMMI SMEs which are established for more than five years. Section 5 outlines the results and section 6 concludes the research work.

\section{CMMI and SPI Awareness in SMEs}

SMEs realize the importance of SPI equally as most of the big organizations do but it is not possible for SMEs to achieve excellence in their software processes easily. Integration of process and quality improvement has already gained popularity across the globe (Singh \& Singh, 2012 and Singh \& Chana, 2013). Different researchers have been working on performance and process maturity of the software SMEs worldwide. O'Connor \& Coleman (2009) have highlighted the underlying critical issues in the adoption of CMMI as SPI model in Irish SMEs. Yang et al. (2005) have come with a study which showed the necessity to evaluate software industry in China. Kim et al. (2010) have explored the impact of open innovation strategy on Korean SMEs. Mishra and Mishra (2008) have studied and analyzed the status of Indian software SMEs. Ali and Ibrahim (2011) have developed an application tool to implement SPI in Malaysia's SME. Dyba (2003) emphasized that SMEs should concentrate on human resource engagement in SPI activities in their organization. Allen et al. (2003) have discussed PRISM as a dedicated guidance model for implementation of SPI in SMEs. The researchers have indicated the availability of an online tool for administrating the SPI activities in SMEs. Garcia et al. (2010) have carried out a methodical survey of related text or literature available for SPI. Pino et al. (2008) have focused on execution of SPI tasks in SMEs. SPI is really crucial for improving the status and maturity level of SMEs. Unavailability and sometimes limited SPI resources like huge SPI initiative cost for its implementation, constrained project completion deadlines have often posed hindrance in SPI adoption and assimilation. Mishra \& Mishra (2008) have suggested and contrasted methodologies for the underlying problems encountered by SMEs in the SPI endeavors. Alexandre et al. (2006) have recommended a method to accelerate SPI endeavors in SMEs. The researchers have presented the solutions of SPI implementation with available budget constraints. Khokhar et al. (2010) have reviewed and identified a number of critical issues and attributes of SPI in SMEs. Sulayman and Mendes (2009) have carried out a survey on SPI initiatives and specific tools and methods for SMEs engaged in web development. SMEs associated 
with web development encountered same issues such as constrained allocation of budget and timelines. These webbased organizations often failed to plan in terms of long term of SPI goals. Sulayman et al. (2012) have proposed a unique framework in pursuit to identify crucial parameters in such web SMEs. Garcia \& Pacheco (2009) have tried to assist SMEs in their initial SPI initiatives. The authors have implemented SPI automation, but certain problems surfaced, and SMEs were not able to access the provided automated system. Pino et al. (2010) have come up with a solution by proposing a technique to handle the underlying limitations. Al-Tarawneh et al. (2011) have suggested incorporation of famous SPI model i.e. CMMI in one of the stages of the proposed framework. The other stage of the framework included one of the agile methodologies i.e. Extreme Programming (XP) for development. The authors have highlighted that the two staged frameworks would definitely improve the software development process.

\subsection{Evolution of Staging and Maturity Levels (MLs)}

An adaptation of ML index has been used to measure continuous improvements and adoptions. It has been originally introduced by Bessant \& Caffyn (1997,1999). Chapman \& Hayland (2000) have refined the model further by index ranges from ML 0: randomness i.e. no activity to ML 5: learning organization (initiate to become an integral part of the organization). The MLs have been shown in Table 1.

Table 1 Software Process Quality Improvement MLs

\begin{tabular}{|l|l|l|}
\hline MLs & Description & Typical characteristics \\
\hline 0 & Random & Activity with no formal efforts \\
\hline 1 & Trying out & $\begin{array}{l}\text { Occurrence attributed to particular difficulty inspired from training guidance, } \\
\text { characterized as confined \& short spanned. }\end{array}$ \\
\hline 2 & Formally Structured & The structured effort, little training, lack integration with business strategy. \\
\hline 3 & Strategic & Efforts towards planned goals, measurement do not take into account such goals. \\
\hline 4 & Empowering & $\begin{array}{l}\text { Strategic processes realized with integration of Top-down focus with bottom-up } \\
\text { actions }\end{array}$ \\
\hline 5 & Learning organization & Sharing the knowledge gathered for adaptations \\
\hline
\end{tabular}

With the passage of time, many authors have discussed step by step progression of maturity and related it with certain kind of innovation (Singh \& Chana, 2012). (Zephir et al. 2011; Garzás \& Paulk, 2013; Ramírez-Mora et al. 2019; Abushama, 2016) have identified many general patterns and synthesized various stage models as following: 1) Top management gets to know about an innovation; 2) a problem matching to the innovation is found; 3) cost of innovation and benefit of adopting the innovation is appraised; 4) process is influenced by many sources positively or negatively; 5) a decision, either adopt or reject the innovation, is made; 6) implementation of innovation is done; 7) examination of decision regarding the novel thing is done and innovation is accepted or rejected;8) the innovation is adopted as a routine and adopted innovation is infused in the organization. Moreover, the staged models had been developed mainly for technical innovations. A process of management innovation has been outlined by Birkinshaw et al. (2008) but that framework dealt with the development of innovations new to the market rather than the adoption of innovations new to the organization.

\subsection{Maturity as a concept in CMMI}

The choice of SPI model is based on a list of factors (Spadoni et al. 2003). These factors include resource availability, cost, business or marketing process need, internal knowledge, timeframe and business strategy (Bibi et al. 2010). Each of the models used however would give an organization some sort of framework through which it can establish the goals and objectives it needs to reach, within some specified period of time (Unterkalmsteiner et al. 2014). Most organizations normally implement a part of some process improvement first to assess its compatibility with the organization, before a full-fledged implementation of the SPI (Küpper et al. 2019). We have concentrated on CMM and CMMI as a base to evaluate the current scenario and trends with respect to maturity attained by SMEs.

\subsubsection{Capability Maturity Model}

CMM is a framework which evaluates the contractor's ability to deliver a qualified product (SEI 2006). The objectives of the model were to improve on software discipline in project cases which were multi-contractor or multi-layered (Sharma \& Sangal, 2018). The basis of the model is the capability of the organization or the project, with respect to five 
levels (Sharma \& Sangal 2019)). Each of these levels has a set of processes that are defined within them. These levels are referred to as maturity levels (Niazi 2008). They are crucial for the prioritization of the steps involved within SPI (Bahsoon et al., 2013; Gill et al., 2019). Additionally, they are important for the identification of the different improvements that can be implemented and increase benefits to the organization within short-term periods (Casale et al., 2016). Also, the model aims at a process's constant improvement (Andrews et al., 2000). The management and organization should constantly strive to improve the software processes and continuously refine them. The evaluation of CMM's Maturity Levels with respect to process, result, and lacking are presented in Table 2.

Table 2 MLs of CMM framework evaluated with respect to process, result and lacking (Khokhar et al., 2010)

\begin{tabular}{|c|c|c|c|c|c|}
\hline Attributes & Level-I Adhoc & Level-II Repeatable & Level-III Defined & $\begin{array}{l}\text { Level-IV } \\
\text { Managed }\end{array}$ & Level-V Optimized \\
\hline Process & Undefined ad hoc & $\begin{array}{l}\text { tracks documents, cost, } \\
\text { schedule, functionality }\end{array}$ & $\begin{array}{c}\text { documented, } \\
\text { standardized, and } \\
\text { tailorable }\end{array}$ & $\begin{array}{c}\text { detailed } \\
\text { measurement; } \\
\text { control }\end{array}$ & $\begin{array}{l}\text { continual process improvement } \\
\text { through quantitative feedback; }\end{array}$ \\
\hline Result & $\begin{array}{l}\text { the outcome } \\
\text { depends on } \\
\text { individuals }\end{array}$ & $\begin{array}{l}\text { repeatable on similar } \\
\text { projects }\end{array}$ & consistency & $\begin{array}{c}\text { process and } \\
\text { products with } \\
\text { quantified quality } \\
\text { predictability }\end{array}$ & Qualified Product \\
\hline Lacking & $\begin{array}{c}\text { any reasonable } \\
\text { process }\end{array}$ & complete process & $\begin{array}{l}\text { predictable } \\
\text { outcomes }\end{array}$ & $\begin{array}{c}\text { the mechanism for } \\
\text { process } \\
\text { improvement }\end{array}$ & N.A. \\
\hline
\end{tabular}

\subsubsection{Capability Maturity Model Integration}

Team (2006) has come up with a new integrated approach known as CMMI which further integrated and standardized CMM while eliminating its limitations. CMMI documents industry best practices categorized on separate areas of interests rather than separate functions. Organizations choose from any of the available models depending on the business objectives, and each model covers all the functional areas. The main concern is to find the difference between CMM and CMMI which is discussed in the following section.

\subsubsection{Comparison of CMM and CMMI}

Process Maturity has been defined in five different levels for CMM and CMMI (Khokhar et al., 2010). These levels are based on significant PAs defined for a particular level. These PAs in CMMI have conquered the architectural flaws existent in CMM processes.

- Level-I (Initial): Immaturity existing in organizations has been regarded as a major characteristic of the initial level i.e. software development processes are not well defined. Organizations at this level have been working in an ad-hoc and reactive manner having undefined processes with no control over processes

- Level-II (Repeatable): Attainment of Level-II of CMM can be realized just by repeating processes for similar type of projects. Level-II of CMMI requires the implementation of requirement management through process planning, performing, measuring, and controlling processes. At CMMI Level II, process is repeatable on similar kind of projects i.e. there exists number of process models which are followed on similar kind of projects.

- Level-III (Defined): Level-III of CMM has emphasized on establishing a consistent process across the organization. Usage of defined and documented standard processes has been used to achieve such kind of consistency. Level III of CMMI can be seen as an enhancement of CMMI Level-II. At CMMI Level III, the organization has a set and defined standard process model, organizational processes, procedures, tools, and methods.

- Level-IV (Managed): CMM Level-IV emphasizes on the attainment of charge over processes. This can be achieved using statistical tools and techniques for measuring the process quantitatively. Similarly, CMMI Level-IV establishes control over processes while identifying sub-processes that can contribute towards efficient processes.

- Level-V (Optimized): CMM Level-V stresses the need to manage processes quantitatively. Whereas managing continuous process improvement quantitatively has been the central point of focus in CMMI Level-V. 
CMM can be seen as a certification instrument but CMMI cannot be. The degree of adoption of CMMI model actually has been taken as a deciding factor for the CMMI Rating (I-V).

\subsubsection{Our Contributions}

The research work attempts to evaluate the maturity levels of Indian SMEs informally i.e. the study has taken a sample of SMEs which are not CMMI certified but otherwise follow CMMI practices. In particular, it presents the results of an evaluation to rate these SMEs on the CMMI scale. This paper has been extending our previous research work (Singh \& Aggarwal, 2017) and aims to point out the facilitating factors in SPI that can really boost the quality of software processes to provide a competitive edge to the software SMEs. It also identifies the top 15 factors encompassing project workflow, team culture, organization culture, SPI culture, organization culture, process guidance, high-level planning, product delivery, alignment and integration, change management, and process improvisation.

After identifying the critical success factors for SPI programs in SMEs in our previous research work (Singh \& Aggarwal, 2017), the present research focusses on the evaluation of unofficial readiness of non-CMMI SMEs. The present research work is motivated by Iqbal et al. (2016) and has taken their work as base. It concentrates on the unofficial readiness for CMMI-based SPI among SMEs, which can be used to define criteria for the selection of SMEs that would be included in SPI initiatives funded by relevant authorities. It differs from existing work for the following reasons:

1. The time of establishment of SMEs was taken as an important parameter for ascertaining the CMMI maturity.

2. The present research work is important and different from others as there is no such existing study for Indian SME.

\section{Research Methodology}

The research methodology adopted for the current study is explained below:

\subsection{Data and Sample}

Descriptive Research Design and Random Stratified Sampling elaborated by Rea \& Parker (2014), Kish (1995) have been used for the present research. Random stratified sampling technique has been used with a sample size of 120 respondents. The sample size seems appropriate as it has been calculated 116 in equation-(i) which is discussed by Rea \& Parker (2014) and Kish (1995).

Size of the sample (SS) can be calculated as follows:

$\mathrm{SS}=\mathrm{Z}^{2} * \mathrm{p} * \mathrm{q} * \mathrm{~N} \quad /\left(\mathrm{e}^{2} *(\mathrm{~N}-1)+\mathrm{Z}^{2} * \mathrm{p} * \mathrm{q}\right)$

Where,

$\mathrm{Z}$ is Level of Confidence

$\mathrm{p}$ is Response Distribution

$\mathrm{q}$ is $(1-\mathrm{p})$

$\mathrm{e}$ is Margin of Error

$\mathrm{N}$ is Population
With the Population size $\mathrm{N}=2000$,

Level of Confidence $=95 \%$

Response Distribution $=50 \%$

Margin of Error $=8 \%$,

$\mathrm{SS}=116$ as per equation -(i)

The sampling unit is India. The response of the respondents has been measured on a five-point likert scale. In all, 300 questionnaires were distributed online through emails to senior, middle and lower level management of software companies. The questionnaires were also given to be filled by senior, middle and lower level management of software companies at nearby places like Chandigarh, Noida, Gurgaon and Delhi using professional references. As many as 163 responses were received, while 120 of them found to be complete in all aspects which formed the basis of this study for further analysis. Out of 120,60 responses were selected on the basis of the time of establishment of the SME in which 30 were established for more than five years and 30 SMEs were established for less than five years. The response rate is good for evaluation CMMI maturity levels for non-SMEs. More elaboration is given in Section 4.2. 
The data was collected from the managers working at 3 different hierarchical levels of Indian SMEs under study. The questionnaire-cum-interview method was used to collect the primary data from the selected respondents. The questionnaire has three sections. The first two sections address the stage of development of SPI in SMEs and also concentrate on finding the effect of time on SPI and organizational capabilities. The third section of the questionnaire has been based on CMMI-DEV v1.3 Process Areas (PAs) and Specific Practices (SPs) exhibited in Table 7. The questionnaire has been designed based on the CMMI Dev V1.3 and detailed discussion with many academicians, professionals and industry experts. The participants have been both identified at random and selected based on professional contacts of the researchers. The pilot testing was done on 28 respondents in totality at three levels of management such as senior, middle and lower level in four companies as mentioned in Table 4. To ensure the quality of the instrument, the questionnaire was tested for reliability, content validity and sensitivity. The questionnaire chosen for the study was found to be reliable as Cronbach's alpha given by Cronbach (1951) and discussed by Nunnally (1978) came to be 0.956 , indicating the goodness of the scale. Content validity of the questionnaire was tested through discussions for comprehensiveness, depth, and relevance to the selected organizations and topic of the study. The questionnaire has been found to be comprehensive, appropriate and relevant to the study as number of changes done based upon the feedback given by experts on academia and industry.

\subsection{For the Organizations}

Universe of Study: Small and Medium Software Development Organizations of India

The present study is focused on SMEs in India. In the context of Indian software industry, the Organization for Economic Cooperation and Development (OECD) categorizes organizations on the basis of their number of employees which has been shown in Table 3 .

Table 3 Size of Software Organizations on the basis of Head Counts

\begin{tabular}{|l|l|}
\hline Category & No. of Employees \\
\hline Very Small & Upto 19 \\
\hline Small & 20 to 99 \\
\hline Medium & 100 to 499 \\
\hline Large & 500 and Above \\
\hline
\end{tabular}

\subsection{Sample Selection:}

This section discusses the sample selection for the research work.

\subsubsection{For the Respondents}

a) Universe of the Study: Managers working at three different levels in the hierarchy existing in the selected organizations.

b) Sample Selection: The respondents have been selected from the organizations under study through the random stratified sampling technique. They have been identified from the various levels of management such as senior level, middle level, and lower level. The respondents present the different positions and role names with respect to their organization. These have been categorized as shown in Table 4.

Table 4 Managers working at three different hierarchical levels.

\begin{tabular}{|l|l|}
\hline Levels of Management & Positions or Roles \\
\hline I. Senior Level & CEO, Chairman, Director, President, Vice-President \\
\hline II. Middle Level & Project Manager, Project Lead, Team Lead, Senior Manager, Senior \\
& Software Engineer, Senior Quality Assurance Manager, Quality Team \\
& Lead \\
\hline III. Lower Level & $\begin{array}{l}\text { Software Engineer, Software Developer, Software Testers, System and } \\
\text { Business Analyst, Trainees }\end{array}$ \\
\hline
\end{tabular}




\section{Trend Evaluation for Maturity Levels in Non-CMMI SMEs}

This section gives appropriate ground to select the time of establishment of SMEs as a significant parameter to study process maturity. It also underlines the methodology and criterion to decide upon maturity levels achieved by NonCMMI SMEs informally.

\subsection{Effect of Time on Process Maturity in SMEs}

This section explores the third research question under study. SEI (2006) reported that the attainment of CMMI level consumes huge time. It is estimated that achieving CMMI level 5 (SCAMPI) takes 54.5 months approximately and time is the cost to be paid for process maturity. Therefore, the present study has selected time being a crucial parameter to be taken into account while making any concrete decision of Maturity levels for non-CMMI SMEs. It has been found that there is a significant effect of time on SPI factors and organizational capabilities which are also depicted in Figure 1 and Finding I discussed in section 4.1.1.

\subsubsection{Effect of Time on SPI Factors and Organizational Capabilities}

Time being the important parameter in deciding the CMMI maturity rating, the factors in Table 5 was explored. The response set on Likert stage has been tabulated in Table 5.

Table 5 Response set for SPI factors and Organizational capabilities

\begin{tabular}{|r|l|c|c|c|c|c|}
\hline & Factors & $\begin{array}{c}\text { Strongly } \\
\text { Disagree }\end{array}$ & Disagree & Neutral & Agree & $\begin{array}{c}\text { Strongly } \\
\text { Agree }\end{array}$ \\
\hline a. & Change in business nature & 6 & 5 & 24 & 34 & 10 \\
\hline b. & Change in business requirement & 3 & 7 & 17 & 49 & 10 \\
\hline c. & Change in demand of resources & 3 & 6 & 21 & 36 & 11 \\
\hline d. & Change in problem complexity & 3 & 2 & 19 & 31 & 4 \\
\hline e. & Change in customer impact & 3 & 3 & 20 & 46 & 7 \\
\hline f. & Change in development methodology & 4 & 2 & 19 & 38 & 16 \\
\hline g. & Change in experience & 3 & 4 & 20 & 38 & 12 \\
\hline h. & Change in technology & 2 & 4 & 11 & 30 & 13 \\
\hline i. & Change in Interdisciplinary impacts & 2 & 4 & 28 & 21 & 5 \\
\hline
\end{tabular}

Changes occur with the passage of time in any Software Process. Numerous factors are depicted in Fig 1 which changes with the time. For each factor, respondents reply (in percentage) for aggregate of agree and strongly agree replies is as follows: Changes in business nature (56\%) and changes in Business requirement (68\%), change in demand of resources $(61 \%)$, change in complexity (59\%), change in customer impact (67\%), Change in development methodology $(68 \%)$, change in experience $(63 \%)$ and change in technology $(72 \%)$.

Finding I: Most significant effects of Time on SPI factors and organizational capabilities are change in technology, change in Business requirement, change in development methodology and change in customer impact are the main factors which prominently changes with time. Change in interdisciplinary impacts is the one factors which not much effected by the time.

Now, we tend to find the effect of time on process maturity and maturity levels for non-CMMI SMEs.

\subsection{Methodology elaborated}

Out of 120 SMEs studied for organizational culture in section 3, 60 SMEs have been found appropriate to be studied and analyzed on the basis of the time of establishment. As the effect of time on process maturity is of main concern for taking any decision on maturity levels, we have divided SMEs into two categories: SMEs established for more than 5 years and SMEs established for less than 5 years. SMEs were selected on the basis of their time of establishment. Among 60 SMEs, 30 SMEs were scrutinized for being established for greater than 5 years and 30 SMEs scrutinized for being established for less than 5 years. 


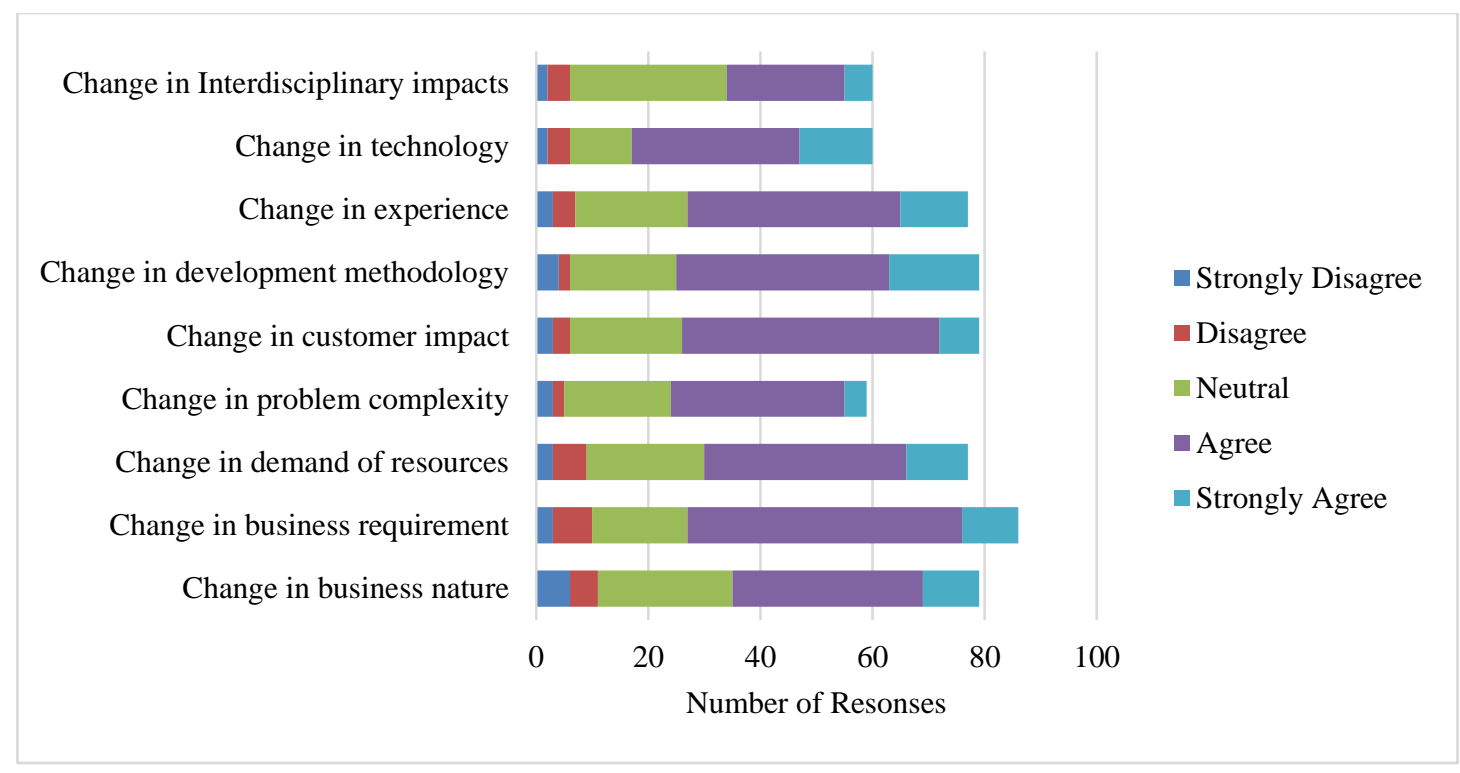

Figure 1 Response regarding SPI factors and organizational capabilities (SPI factors that changes with time and their responses)

\subsection{Criterion to decide on Maturity Level}

Wilkie et al. (2005) studied and categorized PA-SPs set of CMMI- Level-II having high (greater than 70\%), medium (between $70 \%$ and $40 \%$ ) and low (lesser than $40 \%$ ). In a similar study, Iqbal et al. (2016) have used corresponding percentages with a little difference (75\% as a replacement for $70 \%$ and $(50 \%$ as a replacement for $40 \%))$ to reflect the number of SPs in CMMI Level N (1-5) process areas. In the present study, instead of three divisions on the percentage of PA-SPs adopted and practiced by SMEs completing more than five years and SMEs not completing five years, we have divided it into four parts- LOW (<50\%), MEDIUM (50\%-70\%), HIGH (71\%-90\%) and VERY HIGH (> 90\%). Iqbal et al. (2016) have taken more than 50\% adoption of SPs for semi potential organizations and more than $70 \%$ for potential organizations for CMMI rating. In the present study, we are concentrating on the evaluation of the candidature of non-CMMI SMEs for achieved closer to CMMI Maturity Levels. Table 6 presents the comparison of Iqbal et al. (2016) work with our proposed approach for taking up variations in the adoption percentage brackets of CMMI practices. The following criteria or rule has been established in order to confine a Non-CMMI SME for achieving specific CMMI maturity level if it has been found practicing more than $70 \%$ of SPs for that particular maturity level.

Table 6: Comparison of the adoption percentage brackets for CMMI PA-SPs set

\begin{tabular}{|c|c|c|c|c|c|}
\hline Research Work & Low & Medium & High & Very High & Comparison made \\
\hline \multirow[t]{2}{*}{ Iqbal et al. (2016) } & $<50 \%$ & $50 \%-70 \%$ & $>70 \%$ & \multirow[t]{2}{*}{ NA } & \multirow{2}{*}{$\begin{array}{c}\text { Between Small sized and Medium } \\
\text { sized enterprises }\end{array}$} \\
\hline & & Semi Potential & Potential & & \\
\hline $\begin{array}{c}\text { Our Proposed } \\
\text { Approach (Rule } \\
\text { ML) }\end{array}$ & $<50 \%$ & $50 \%-70 \%$ & $71 \%-90 \%$ & $>90 \%$ & $\begin{array}{c}\text { Between SMEs (estb. < } 5 \text { years) } \\
\text { and SMEs (estb. >5years) }\end{array}$ \\
\hline
\end{tabular}

Here, we have been emphasizing on Specific Practices (SPs) of respective Process Areas (PAs) in particular Maturity Level (MLs). SPs is a set of activities defined in CMMI v1.3 which are essential for achieving Specific Goals (SGs) of PAs. Team (2010) in their technical report has described the 22 PAs and 167 SPs. Based upon the work of Team (2010), we have developed the measuring instrument having major PAs with respective SPs in that particular PA. In the following Table 7, we have incorporated count (\#) of SPs, in particular PA and further associated the PA and SPs with the ML Rating. 
Table 7 Measuring instrument containing PAs with count of SPs and associated ML for CMMI-DEV v1. $3^{1}$

\begin{tabular}{|c|c|c|c|c|c|c|c|c|c|}
\hline $\begin{array}{l}\text { S. } \\
\text { no. }\end{array}$ & Process Areas (PAs) & $\begin{array}{l}\text { Acronym } \\
\text { used for } \\
\text { PAs }\end{array}$ & SPs & ML & $\begin{array}{l}\text { S. } \\
\text { no. }\end{array}$ & Process Areas (PAs) & $\begin{array}{l}\text { Acronym } \\
\text { used for } \\
\text { PAs }\end{array}$ & SPs & ML \\
\hline 1 & $\begin{array}{l}\text { Requirements } \\
\text { Management }\end{array}$ & REQM & 5 & 2 & 12 & Organizational Training & OT & 7 & 3 \\
\hline 2 & Project Planning & PP & 14 & 2 & 13 & Product Integration & PI & 9 & 3 \\
\hline 3 & $\begin{array}{l}\text { Project Monitoring and } \\
\text { Control }\end{array}$ & PMC & 10 & 2 & 14 & Requirements Development & $\mathrm{RD}$ & 10 & 3 \\
\hline 4 & $\begin{array}{l}\text { Process and Product } \\
\text { Quality Assurance }\end{array}$ & PPQA & 4 & 2 & 15 & Risk Management & RSKM & 7 & 3 \\
\hline 5 & $\begin{array}{l}\text { Configuration } \\
\text { Management }\end{array}$ & $\mathrm{CM}$ & 7 & 2 & 16 & Technical Solution & TS & 6 & 3 \\
\hline 6 & $\begin{array}{l}\text { Measurement and } \\
\text { Analysis }\end{array}$ & MA & 8 & 2 & 17 & Validation & VAL & 5 & 3 \\
\hline 7 & $\begin{array}{l}\text { Supplier Agreement } \\
\text { Management }\end{array}$ & SAM & 6 & 2 & 18 & Verification & VER & 8 & 3 \\
\hline 8 & $\begin{array}{l}\text { Decision Analysis and } \\
\text { Resolution }\end{array}$ & DAR & 6 & 3 & 19 & $\begin{array}{l}\text { Organizational Process } \\
\text { Performance }\end{array}$ & OPP & 5 & 4 \\
\hline 9 & $\begin{array}{l}\text { Integrated Project } \\
\text { Management }\end{array}$ & IPM & 7 & 3 & 20 & $\begin{array}{l}\text { Quantitative Project } \\
\text { Management }\end{array}$ & QPM & 7 & 4 \\
\hline 10 & $\begin{array}{l}\text { Organizational Process } \\
\text { Definition }\end{array}$ & OPD & 7 & 3 & 21 & $\begin{array}{l}\text { Organizational Performance } \\
\text { Management }\end{array}$ & OPM & 10 & 5 \\
\hline 11 & $\begin{array}{l}\text { Organizational Process } \\
\text { Focus }\end{array}$ & OPF & 9 & 3 & 22 & $\begin{array}{l}\text { Causal Analysis and } \\
\text { Resolution }\end{array}$ & CAR & 5 & 5 \\
\hline
\end{tabular}

\subsubsection{Possible number of specific practices in particular CMMI Level}

Table 8 shows the possible number of specific practices in particular for CMMI Level 2 according to the approach in Table 6 for Rule ML.

Table 8. Possible number of specific practices in CMMI Level 2 under relevant percentages

\begin{tabular}{|c|c|c|c|c|c|}
\hline Process Areas & $\begin{array}{c}\text { No. of specific practices in the } \\
\text { various process areas of } \\
\text { CMMI level 2 }\end{array}$ & Less than 50\% & $50 \%-70 \%$ & $71 \%-90 \%$ & $\begin{array}{c}\text { Greater than } \\
90 \%\end{array}$ \\
\hline PPQA & 4 & 0,1 & 2 & 3 & 4 \\
\hline REQM & 5 & $0,1,2$ & 3 & 4 & 5 \\
\hline SAM & 6 & $0,1,2,3$ & 4 & 5 & 6 \\
\hline CM & 7 & $0,1,2,3$ & 4 & 5,6 & 7 \\
\hline MA & 8 & $0,1,2,3$ & 4,5 & 6,7 & 10 \\
\hline PMC & 10 & $0,1,2,3,4$ & $5,6,7$ & 8,9 & 13,14 \\
\hline PP & 14 & $0,1,2,3,4,5,6$ & $7,8,9$ & $10,11,12$ & 8 \\
\hline
\end{tabular}

Table 9 shows the possible number of specific practices in particular for CMMI Level 3 according to the approach in Table 6 for Rule ML.

\footnotetext{
${ }^{1}$ http://www.sei.cmu.edu/library/assets/whitepapers/CMMI\%20DEV\%20v1\%203\%20-\%20TR\%2011-2010\%20Dutch.pdf, retrieved on July 23,2016 
Table 9. Possible number of specific practices in CMMI Level 3 under relevant percentages

\begin{tabular}{|c|c|c|c|c|c|}
\hline & $\begin{array}{l}\text { No. of specific practices } \\
\text { in the various process } \\
\text { areas of CMMI level } 3\end{array}$ & $\begin{array}{c}\text { Less than } \\
50 \%\end{array}$ & $50 \%-70 \%$ & $71 \%-90 \%$ & $\begin{array}{c}\text { Greater than } \\
90 \%\end{array}$ \\
\hline IPM & 7 & $0,1,2,3$ & 4 & 5,6 & 7 \\
\hline OPD & 7 & $0,1,2,3$ & 4 & 5,6 & 7 \\
\hline OT & 7 & $0,1,2,3$ & 4 & 5,6 & 7 \\
\hline PI & 9 & $0,1,2,3,4$ & 5,6 & 7,8 & 9 \\
\hline RD & 10 & $0,1,2,3,4$ & $5,6,7$ & 8,9 & 10 \\
\hline VER & 8 & $0,1,2,3$ & 4,5 & 6,7 & 8 \\
\hline
\end{tabular}

\subsubsection{RULE ML}

To decide on maturity levels (ML) for non-CMMI certified SMEs, Rule ML has been established to assign a particular maturity level to given SMEs. Rule ML is based on the strategies used by Wilkie et al. (2005) and Iqbal et al. (2016) with little modifications in percentages of specific practices followed in order to decide CMMI Level of software organization which are not CMMI certified. The underlying variation in adoption brackets for Iqbal et al. (2016) and our proposed approach is discussed in Table 6 in section 4.3. Rule ML follows Table 8 and Table 9 for possible number of specific practices in CMMI Level 3 under relevant percentages. Algorithm for Rule ML is further discussed in the following section:

Algorithm: Rule ML

$\begin{array}{ll}\text { DEFINE Adoption Bracket } & \text { HIGH }(71 \%-90 \%) \\ \text { DEFINE Adoption Bracket } & \text { VERY HIGH }(>90 \%)\end{array}$

INPUT: PA and SP followed by Non-CMMI organizations, Table 8 and Table 9

OUTPUT: CMMI level

BEGIN

FOR (Non-CMMI SMEs)

FOR (Particular PA and SP set at CMMI Level N)

IF (Acceptance and Adoption percentage in the range HIGH OR VERY HIGH> 70\%) THEN

Assign SME to prospective CMMI Level N

ELSE

Assign SME to Still Struggling List for CMMI Level N

END FOR

END FOR

END

According to the Rule ML, the organizations that agreed to follow CMMI level 2 practices in the bracket 71-90\% will go in the prospective list of CMMI Level 2 companies. The organizations which are following the CMMI level 2 
practices less than $70 \%$ and are in the bracket $50-70 \%$ will go to still struggling list for CMMI level2. Similarly, for CMMI level 3 the organizations need to follow more than $70 \%$ of specific practices of respective process areas of CMMI level 3. The actual percentage of organizations following specific practices in 71-90\% bracket and more than 90\% are put in the prospective list. The total percentage is calculated by summing up these two brackets. The organizations which are not following specific practices upto 70\% are put in still struggling list CMMI level 3. We have made the comparison on the basis of CMMI PA and SP followed between SMEs established for less than 5 years and SMEs established for more than 5 years in Section 4.4.

\subsection{CMMI Level-II PAs and SPS}

Table 10 depicting the number of responses received for CMMI LEVEL-II based survey questionnaire. We have segregated the response according to the acceptance and adoption percentage as LOW (<50\%), MEDIUM (50\% - 70\%), HIGH (71\% - 90\%) and VERY HIGH (> 90\%) for SPs of CMMI Level-II processes and specific practices by noncertified SMEs.

Table 10 CMMI Level -II PA-SPs with adoption percentage in SMEs established for more than 5 years and SMEs established for less than 5 years.

\begin{tabular}{|c|c|c|c|c|c|c|c|c|c|c|c|c|c|c|c|c|c|c|}
\hline \multirow[t]{3}{*}{ PA } & \multicolumn{4}{|c|}{$<50 \%$} & \multicolumn{4}{|c|}{$50 \%-70 \%$} & \multicolumn{4}{|c|}{$71 \%-90 \%$} & \multicolumn{4}{|c|}{$>90 \%$} & \multirow{2}{*}{\begin{tabular}{l}
\multicolumn{1}{c}{ Avg } \\
SME \\
$>5 \mathrm{yrs}$
\end{tabular}} & \multirow{2}{*}{\begin{tabular}{l}
\multicolumn{1}{c}{ Avg } \\
SME \\
$<5 y r s$
\end{tabular}} \\
\hline & \multicolumn{2}{|c|}{$\begin{array}{l}\text { SME } \\
>5 \mathrm{yr} \\
\mathrm{s}\end{array}$} & \multicolumn{2}{|c|}{$\begin{array}{l}\text { SME }< \\
5 y r s\end{array}$} & \multicolumn{2}{|c|}{$\begin{array}{l}\text { SME } \\
>5 \mathrm{yrs}\end{array}$} & \multicolumn{2}{|c|}{$\begin{array}{l}\text { SME } \\
<5 y r s\end{array}$} & \multicolumn{2}{|c|}{$\begin{array}{l}\text { SME } \\
>5 \mathrm{yrs}\end{array}$} & \multicolumn{2}{|c|}{$\begin{array}{l}\text { SME } \\
<5 y r s\end{array}$} & \multicolumn{2}{|c|}{$\begin{array}{l}\text { SME } \\
>5 \mathrm{yrs}\end{array}$} & \multicolumn{2}{|c|}{$\begin{array}{l}\text { SME } \\
<5 y r s\end{array}$} & & \\
\hline & $\begin{array}{l}\# \\
\mathrm{~A}\end{array}$ & $\begin{array}{l}\% \\
\text { B }\end{array}$ & $\begin{array}{l}\# \\
\mathrm{C}\end{array}$ & $\begin{array}{l}\% \\
\mathrm{D}\end{array}$ & $\begin{array}{l}\# \\
\mathrm{E}\end{array}$ & $\begin{array}{l}\% \\
\mathrm{~F}\end{array}$ & $\begin{array}{l}\# \\
\mathrm{G}\end{array}$ & $\begin{array}{l}\% \\
\mathrm{H}\end{array}$ & \begin{tabular}{c|}
$\#$ \\
$\mathrm{I}$
\end{tabular} & $\begin{array}{l}\% \\
\mathrm{~J}\end{array}$ & $\begin{array}{l}\# \\
\mathrm{~K}\end{array}$ & $\begin{array}{l}\% \\
\mathrm{~L}\end{array}$ & $\begin{array}{l}\# \\
M\end{array}$ & $\begin{array}{l}\% \\
\mathrm{~N}\end{array}$ & $\begin{array}{l}\# \\
\mathrm{O}\end{array}$ & $\begin{array}{l}\% \\
\mathrm{P}\end{array}$ & $\begin{array}{l}\% \\
Q=J+N\end{array}$ & $\begin{array}{l}\% \\
\mathrm{R}=\mathrm{L}+\mathrm{P}\end{array}$ \\
\hline REQM & 0 & 0 & 2 & 6 & 1 & 3 & 5 & 16 & 4 & 13 & 3 & 10 & 25 & 83 & 20 & 67 & 96 & 77 \\
\hline $\mathrm{PP}$ & 0 & 0 & 1 & 3 & 2 & 6 & 8 & 26 & 5 & 16 & 5 & 16 & 23 & 77 & 16 & 53 & 93 & 69 \\
\hline PMC & 1 & 3 & 1 & 3 & 1 & 3 & 7 & 23 & 4 & 13 & 4 & 13 & 24 & 80 & 18 & 60 & 93 & 73 \\
\hline PPQA & 2 & 6 & 3 & 10 & 3 & 10 & 7 & 23 & 4 & 13 & 4 & 13 & 21 & 70 & 16 & 53 & 83 & 66 \\
\hline $\mathrm{CM}$ & 0 & 0 & 2 & 6 & 2 & 6 & 4 & 13 & 6 & 20 & 5 & 16 & 22 & 73 & 19 & 63 & 93 & 79 \\
\hline MA & 2 & 6 & 3 & 10 & 3 & 10 & 5 & 16 & 5 & 16 & 6 & 20 & 20 & 67 & 14 & 47 & 83 & 67 \\
\hline SAM & 0 & 0 & 3 & 10 & 2 & 6 & 6 & 20 & 3 & 10 & 4 & 13 & 25 & 83 & 17 & 57 & 93 & 70 \\
\hline AVG \% & & & & & & & & & & & & & & & & & 91 & 71 \\
\hline
\end{tabular}

We have formulated a RULE ML described in section 4.3.2 for deciding the CMMI Maturity Level of a particular SME. According to the rule, number of processes and SPs should lie in the HIGH and VERY HIGH zone as perceived value to achieve particular level. SEI (2006) reported that the attainment of CMMI level consumes huge time. It is estimated that achieving CMMI level 5 (SCAMPI) takes 54.5 months (5 years (yrs) approximately) approximately and time is the cost to be paid for process maturity.

I) SMEs (Established (Estb.) $>5$ yrs)

- We have found while concentrating on the second last field i.e. Q which is the sum of the two fields i.e. $J$ and $N$ that $96 \%$ of SMEs pursued more than 70\% of SPs followed for REQM processes in SMEs (Estb. > 5yrs). Similarly, for the processes PP, PMC, PPQA, CM, MA and SAM 93\%, 94\%, 83\%, 95\%, 83\% and 95\% SMEs (Estb. > 5yrs) respectively have been pursuing greater than 70\% of SPs of CMMI-Level-II processes.

- These all are quite high figures and are appropriate to recognize that a good number of SMEs i.e. which are established for more than 5 years are following at least $70 \%$ of the processes in CMMI-Level-II.

- It has also been found while concentrating on $N$ field i.e. the number of SMEs (Estb $>5$ yrs) following more than $90 \%$ of the SPs of CMMI-Level-II is high (i.e. 77\%). The field N shows the percentage i.e. Greater than $70 \%$ of SMEs (Estb $>5 \mathrm{yrs}$ ) are following $90 \%$ of the SPs for CMMI-Level-II processes.

- It is very interesting to note the fact that $90 \%$ of the SPs are being followed in $70 \%$ to $83 \%$ of non-certified SMEs established for greater than 5 years as the values of $\mathrm{N}$ column lies between $70 \%-83 \%$.

- Focusing on P and L fields collectively i.e. $70 \%$ to $100 \%$ block (all together), greater SMEs (Estb. >5yrs) lie in P field of $>90 \%$ block and lesser SMEs (Estb. $>5 \mathrm{yrs}$ ) lie in L field of $71 \%-90 \%$ block.

- On an average, $91 \%$ of SMEs (Estb. $>5$ yrs) follow greater than $70 \%$ of SPs of CMMI-Level-II. 
Summarizing the case of non-CMMI SMEs (Estb. > 5 yrs) Follow-up of 90\%-100\% SPs by $67 \%$ to $83 \%$ of SMEs which are established for more than 5 years

- Follow-up of $71 \%-100 \%$ SPs by $83 \%$ to $96 \%$ of SMEs which are established for more than 5 years

II) SMEs (Estb. $<5$ yrs)

- The last field of Table 10 i.e. $\mathrm{R}$ gives the sum of $\mathrm{L}$ and $\mathrm{P}$ which establishes that $77 \%$ of SMEs followed greater than $70 \%$ of SPs followed for REQM processes in SMEs (Estb. < 5yrs). Similarly, for the processes PP, PMC, PPQA, CM, MA and SAM 69\%, 73\%, 66\%, 79\%, 67\% and 70\% SMEs (Estb. < 5yrs) respectively have been following greater than $70 \%$ of SPs of CMMI Level-II processes.

- As good number of SMEs which are established for less than 5 years are following at least $70 \%$ of the processes in CMMI Level-II.

- It has also been found while focusing on the P field i.e. number of SMEs (Estb. $<5$ yrs) following greater than $90 \%$ of the SPs of CMMI Level-II is not reaching high. REQM, PP, PMC, PPQA, CM, MA and SAM in P field shows the \%age of SMEs (Estb. < 5 yrs) are following $90 \%$ of the SPs for CMMI Level-II processes is $67 \%, 53 \%, 60 \%, 53 \%, 63 \%, 47 \%$ and $57 \%$ respectively. Only $47 \%$ of SMEs (Estb. <5 yrs) are following $90 \%$ of SPs for Measurement and Analysis (MA). $90 \%$ of SPs of PP and PPQA are followed by $53 \%$ of SMEs. PMC, CM and REQM for $90 \%$ of SPs being followed by $60 \%, 63 \%$ and $67 \%$ of SMEs (Estb. < 5 yrs)

- Though figures are not reaching high but it is very interesting to note the fact that $90 \%$ of the SPs are being followed in 53\% to $67 \%$ of non-certified SMEs established for less than 5 years.

- Focusing on P and L fields collectively i.e. $70 \%$ to $100 \%$ block (all together), more SMEs (Estb. < 5yrs) lie in P field of $>90 \%$ block and lesser SMEs (Estb. < 5yrs) lie in L field of 71\%-90\% block.

- On an average, $71 \%$ of SMEs (Estb. $<5$ yrs) follow greater than $70 \%$ of SPs of CMMI Level-II.

Summarizing for non-CMMI SMEs (Estb. $<5$ yrs)

- Follow-up of $90 \%-100 \%$ SPs by 53 to $67 \%$ of non-certified SMEs which are established for less than 5 years.

- Follow-up of $71 \%-100 \%$ SPs by $83 \%$ to $96 \%$ of non-certified SMEs which are established for greater than 5 years.

4.4.1 Statistical Analysis and Validation

Table 11 T-Test for CMMI Level 2

\begin{tabular}{|c|c|c|c|c|c|c|c|c|c|}
\hline \multirow{3}{*}{\multicolumn{2}{|c|}{$\begin{array}{l}\text { SMEs in different adoption } \\
\text { brackets }\end{array}$}} & \multicolumn{5}{|c|}{ Differences } & \multirow{4}{*}{$\frac{\mathrm{t}}{-3.873}$} & \multirow{4}{*}{$\mathrm{df}$} & \multirow{4}{*}{$\begin{array}{l}\begin{array}{l}\text { Sig. } \\
(2- \\
\text { tailed })\end{array} \\
.008\end{array}$} \\
\hline & & \multirow{3}{*}{$\begin{array}{l}\text { Mean } \\
-1.429\end{array}$} & \multirow{3}{*}{$\begin{array}{r}\begin{array}{c}\text { Std. } \\
\text { Deviation }\end{array} \\
.976\end{array}$} & \multirow{3}{*}{$\begin{array}{l}\begin{array}{l}\text { Std. } \\
\text { Error } \\
\text { Mean }\end{array} \\
.369\end{array}$} & \multicolumn{2}{|c|}{$\begin{array}{l}\text { 95\% Confidence } \\
\text { Interval of the } \\
\text { Difference }\end{array}$} & & & \\
\hline & & & & & Lower & Upper & & & \\
\hline Pair 1 & $\begin{array}{l}\text { SME (estb. }>5 \text { years) - } \\
\text { SME (estb. }<5 \text { years) } \\
\text { years) following }<50 \% \\
\text { processes }\end{array}$ & & & & -2.331 & -.526 & & & \\
\hline Pair 2 & $\begin{array}{l}\text { SME (estb.> } 5 \text { years) - } \\
\text { SME (estb. < } 5 \text { years) } \\
\text { following } 50-70 \% \\
\text { processes }\end{array}$ & -4.000 & 1.633 & .617 & -5.510 & -2.490 & -6.481 & 6 & .001 \\
\hline Pair 3 & $\begin{array}{l}\text { SME (estb.> } 5 \text { years) - } \\
\text { SME (estb. < 5 years) } \\
\text { following } 71-90 \% \\
\text { processes }\end{array}$ & 0.000 & .816 & .309 & -.755 & .755 & 0.000 & 6 & 1.000 \\
\hline Pair 4 & $\begin{array}{l}\text { SME (estb.> } 5 \text { years) - } \\
\text { SME(estb. }<5 \text { years) } \\
\text { following }>90 \% \\
\text { processes }\end{array}$ & 5.714 & 1.604 & .606 & 4.231 & 7.197 & 9.428 & 6 & .000 \\
\hline
\end{tabular}


Student T-test is applied on the response set received from SMEs established for more than 5 years and SMEs established for fewer than 5 years following CMMI Level 2 PA-SPs set in different adoption brackets processes to evaluate the difference. Munro (2005) and Cohen (1992) elaborated T-test as a type of inferential statistic used to determine if there is a significant difference between the means of two groups, which may be related in certain features. Table 11 shows the result of student T-test statistic applied.

Pair 3 shows that there is no significant difference between the specific practices followed in SMEs (estb. $>5$ years) and SMEs (estb. $<5$ years) as calculated $t$ value (sig. 2 tailed) is more than actual $t$ value. This means more than $70 \%$ specific practices for respective PAs of CMMI level 2 are followed by both types of organizations taken as a sample.

Pair 4 also shows that there is a significant difference between the specific practices followed in SMEs (estb. $>5$ years) and SMEs (estb. < 5 years) as calculated t value (sig. 2 tailed) is less than actual t value. This means SMEs (estb. > 5 years) follow greater than $90 \%$ of specific practices whereas SMEs (estb. $<5$ years) lie in the $71-90 \%$ or lesser brackets.

\subsection{CMMI Level-III PAs and SPS}

Table 12 depicts a number of responses received from CMMI LEVEL-III based survey questionnaire. We have segregated the response according to the acceptance and adoption percentage as LOW (<50\%), MEDIUM (50\% -70\%), HIGH (71\%-90\%) and VERY HIGH (> 90\%) for SPs of CMMI Level-II processes and specific practices by noncertified SMEs.

Table 12 CMMI Level-III PA-SPs with adoption percentage in SMEs established for more than 5 years and SMEs established for less than 5 years.

\begin{tabular}{|c|c|c|c|c|c|c|c|c|c|c|c|c|c|c|c|c|c|c|}
\hline \multirow[t]{3}{*}{$\mathrm{PA}$} & \multicolumn{4}{|c|}{$<50$} & \multicolumn{4}{|c|}{$50 \%-70 \%$} & \multicolumn{4}{|c|}{$71 \%-90 \%$} & \multicolumn{4}{|c|}{$>90 \%$} & \multirow{2}{*}{$\begin{array}{l}\text { AVG } \\
\text { SME } \\
>5 \mathrm{yrs} \\
\end{array}$} & \multirow{2}{*}{$\begin{array}{l}\text { AVG } \\
\text { SME } \\
<5 y r s\end{array}$} \\
\hline & \multicolumn{2}{|c|}{$\begin{array}{l}\text { SME } \\
>5 \mathrm{yrs}\end{array}$} & \multicolumn{2}{|c|}{$\begin{array}{l}\text { SME } \\
<5 \mathrm{yrs} \\
\end{array}$} & \multicolumn{2}{|c|}{$\begin{array}{l}\text { SME } \\
>5 \mathrm{yrs}\end{array}$} & \multicolumn{2}{|c|}{$\begin{array}{l}\text { SME } \\
<5 y r s\end{array}$} & \multicolumn{2}{|c|}{$\begin{array}{l}\text { SME } \\
>5 \mathrm{yrs}\end{array}$} & \multicolumn{2}{|c|}{$\begin{array}{l}\text { SME } \\
<5 \mathrm{yrs}\end{array}$} & \multicolumn{2}{|c|}{$\begin{array}{l}\text { SME } \\
>5 \mathrm{yrs}\end{array}$} & \multicolumn{2}{|c|}{$\begin{array}{l}\text { SME } \\
<5 y r s\end{array}$} & & \\
\hline & \begin{tabular}{l|}
$\#$ \\
$\mathrm{~A}$
\end{tabular} & $\begin{array}{l}\% \\
B\end{array}$ & & $\begin{array}{l}\% \\
D\end{array}$ & & $\begin{array}{l}\% \\
F\end{array}$ & $\begin{array}{l}\# \\
\mathrm{G}\end{array}$ & $\begin{array}{l}\% \\
\mathrm{H}\end{array}$ & $\begin{array}{l}\# \\
\text { I }\end{array}$ & $\begin{array}{l}\% \\
\mathrm{~J}\end{array}$ & $\begin{array}{l}\# \\
\mathrm{~K}\end{array}$ & $\begin{array}{l}\% \\
\mathrm{~L}\end{array}$ & $\begin{array}{l}\# \\
M\end{array}$ & $\begin{array}{l}\% \\
\mathrm{~N}\end{array}$ & $\begin{array}{l}\# \\
\mathrm{O}\end{array}$ & $\begin{array}{l}\% \\
P\end{array}$ & $\begin{array}{l}\% \\
Q=N+J\end{array}$ & \\
\hline DAR & 1 & 3 & 4 & 13 & 1 & 3 & 10 & 33 & 25 & 83 & 15 & 50 & 3 & 10 & 1 & 3 & 93 & 53 \\
\hline IPM & 2 & 6 & 5 & 16 & 2 & 6 & 9 & 30 & 21 & 70 & 14 & 47 & 5 & 16 & 2 & 6 & 86 & 53 \\
\hline OPD & 0 & 0 & 4 & 13 & 1 & 3 & 11 & 36 & 25 & 83 & 13 & 43 & 4 & 13 & 2 & 6 & 96 & 49 \\
\hline OPF & 3 & 10 & 7 & 23 & \begin{tabular}{|l|}
3 \\
\end{tabular} & 10 & 7 & 23 & 23 & 77 & 16 & 53 & 1 & 3 & 0 & 0 & 80 & 53 \\
\hline OT & 1 & 3 & 4 & 13 & 1 & 3 & 8 & 27 & 23 & 77 & 14 & 47 & 5 & 16 & 3 & 10 & 93 & 57 \\
\hline PI & 3 & 10 & 6 & 20 & 4 & 13 & 9 & 30 & 20 & 67 & 13 & 43 & 3 & 10 & 2 & 6 & 77 & 49 \\
\hline $\mathrm{RD}$ & 2 & 6 & 6 & 20 & 4 & 13 & 7 & 23 & 22 & 73 & 16 & 53 & 4 & 13 & 1 & 3 & 86 & 56 \\
\hline RSKM & 1 & 3 & 6 & 20 & 1 & 3 & 8 & 27 & 25 & 83 & 15 & 50 & 3 & 10 & 1 & 3 & 93 & 53 \\
\hline TS & 2 & 6 & 5 & 16 & \begin{tabular}{|l|}
3 \\
\end{tabular} & 10 & 7 & 23 & 23 & 77 & 14 & 47 & 2 & 6 & 2 & 6 & 83 & 53 \\
\hline VAL & 1 & 3 & 6 & 20 & 2 & 6 & 9 & 30 & 22 & 73 & 14 & 47 & 6 & 20 & 1 & 3 & 93 & 50 \\
\hline VER & \begin{tabular}{l|l} 
\\
\end{tabular} & 0 & 5 & 16 & 1 & 3 & 7 & 23 & 24 & 80 & 15 & 50 & 5 & 16 & 2 & 6 & 96 & 56 \\
\hline AVG\% & & & & & & & & & & & & & & & & & 88 & 52 \\
\hline
\end{tabular}

We have formulated the RULE ML described in section 4.3.2 for the CMMI ML of a particular SME. According to the rule, a greater number of processes and SPs should lie in the HIGH and VERY HIGH zone as perceived value to achieve that particular CMMI maturity level. Rule ML is based on the strategies followed by Wilkie et al. (2005) and Iqbal et al. (2016) with little modifications in percentages of specific practices followed in order to decide CMMI Level of software organization which are not CMMI certified. RULE ML follows the adoption percentage brackets for CMMI PA-SPs set given in Table 6 for the proposed approach. The threshold value is considered as more than $70 \%$ as per the exiting study by Iqual et. al (2016).

I) SMEs (Estb. $>5$ yrs)

- We have found while concentrating on the second last field i.e. Q which is the sum of the two fields i.e. J and $\mathrm{N}$ that $93 \%$ of SMEs followed greater than $70 \%$ of SPs for DAR processes in SMEs (Estb. > 5yrs). Similarly, for the processes IPM, OPD, OPF, OT, PI, RD, RSKM, TS, VAL and VER, $86 \%, 96 \%, 80 \%$, 
93\%, 77\%, 86\%, 93\%, 83\%, 93\% and 96\% SMEs (Estb>5yrs) respectively have been following greater than $70 \%$ of SPs of CMMI Level-III processes.

- These all are quite high figures and are appropriate to recognize that a good number of SMEs i.e. which are established for greater than 5 years are following at least $70 \%$ of the processes in CMMI Level-III.

- It has also been found while concentrating on M field that number of SMEs (Estb.>5 yrs) following greater than $90 \%$ of the SPs of CMMI Level-III lie in this field are quite low. In N field, only $3 \%$ to $20 \%$ SMEs (Estb.>5 yrs) are following greater than $90 \%$ of the SPs for CMMI Level-II processes.

- It has been noted that $90 \%$ of the SPs are being followed in 3\% to $20 \%$ of non-certified SMEs established for greater than 5 years.

- Focusing on $\mathrm{J}$ and $\mathrm{N}$ fields collectively i.e. $71 \%$ to $100 \%$ block (all together), more SMEs (Estb.>5yrs) lie in P field of 71\%-90\%block and lesser SMEs (Estb.>5yrs) lie in L field of $>90 \%$ block.

- On an average, $88 \%$ of SMEs (Estb. $>5 \mathrm{yrs}$ ) follow greater than $70 \%$ of SPs of CMMI Level-III.

Summarizing in case of non-certified SMEs (Estb. >5 yrs)

- Follow-up of $90 \%-100 \%$ SPs by $0-10 \%$ of non-certified SMEs which are established for more than 5 years

- Follow-up of 70\%-100\% SPs by 80\%-96\% of SMEs which are established for more than 5 years

II) SMEs (Estb. $<5$ yrs)

- Last field of Table 12 i.e. $\mathrm{R}$ gives the sum of $\mathrm{L}$ and $\mathrm{P}$ which establishes that $53 \%$ of SMEs followed greater than $70 \%$ of SPs followed for DAR processes in SMEs (Estb. < 5yrs). Similarly, for the processes IPM, OPD, OPF, OT, PI, RD, RSKM, TS, VAL and VER 53\%,49\%,53\%,57\%,49\%,56\%,53\%,53\%,50\%and 56\%. SMEs (Estb <5yrs) respectively have been following greater than $70 \%$ of SPs of CMMI Level-III processes.

- Approximately 50\% SMEs which are established for less than 5 years are following at least $70 \%$ of the processes in CMMI Level-II.

- It has also been found while focusing on P-field that a few numbers of SMEs (Estb $<5$ yrs) following greater than $90 \%$ of the SPs of CMMI Level-III. SPs in DAR,IPM, OPD, OPF, OT, PI, RD, RSKM,TS,VAL and VER in P field shows the \%age of SMEs (Estb. $<5$ yrs) are following $90 \%$ of the SPs for CMMI Level-III processes is 3,6,6,0,10,6,3,3,6,3 and 6 respectively. $0 \%$ of SMEs (Estb. $<5$ yrs) are following $90 \%$ of SPs for OPF. $90 \%$ of SPs of IPM, OPD, PI, TS, and VER are followed by $6 \%$ of SMEs. OT for $90 \%$ of SPs being followed by $10 \%$ of SMEs (Estb.<5 yrs). Only 3\% SMEs (Estb. <5yrs) follow greater than $90 \%$ SPs for DAR, RD, RSKM and VAL.

- Though figures are not reaching high, but it is very interesting to note the fact that $90 \%$ of the SPs are being followed in 0-10\% of non-certified SMEs established for less than 5 years.

- Focusing on P and L fields collectively i.e. $71 \%$ to $100 \%$ block (altogether), greater SMEs (Estb. <5yrs) lie in P field of 71\%-90\% block and lesser SMEs (Estb.<5yrs) lie in L field of >90\% block for CMMI Level-III.

- On an average, $52 \%$ of SMEs (Estb. $<5$ yrs) follow greater than $70 \%$ of SPs of CMMI Level-III.

Summarizing the case of non-CMMI SMEs (Estb. $<5$ yrs)

- Follow-up of 90\%-100\% SPs by 0\%-10\% of non-certified SMEs which are established for less than 5 years.

- Follow-up of $71 \%-100 \%$ SPs by $83 \%$ to $96 \%$ of non-certified SMEs which are established for greater than 5 years

4.5.1 Statistical Analysis and Validation

Student T-test is applied on the response set received from SMEs established for more than 5 years and SMEs established for lesser than 5 years following CMMI Level 2 PA-SPs set in different adoption brackets processes to evaluate the difference. Munro (2005) elaborated T-test as a type of inferential statistic used to determine if there is a significant difference between the means of two groups, which may be related in certain features. Table 13 shows the result of student T-test statistic applied. 
Table 13. T- Test for CMMI Level 2

\begin{tabular}{|c|c|c|c|c|c|c|c|c|c|}
\hline \multirow{3}{*}{\multicolumn{2}{|c|}{$\begin{array}{l}\text { SMEs in different adoption } \\
\text { brackets }\end{array}$}} & \multicolumn{5}{|c|}{ Differences } & \multirow[b]{3}{*}{$\mathrm{t}$} & \multirow[b]{3}{*}{ df } & \multirow{3}{*}{$\begin{array}{l}\text { Sig. (2- } \\
\text { tailed) }\end{array}$} \\
\hline & & \multirow[b]{2}{*}{ Mean } & \multirow{2}{*}{$\begin{array}{c}\text { Std. } \\
\text { Deviation }\end{array}$} & \multirow{2}{*}{$\begin{array}{l}\text { Std. } \\
\text { Error } \\
\text { Mean }\end{array}$} & \multicolumn{2}{|c|}{$\begin{array}{l}95 \% \text { Confidence } \\
\text { Interval of the } \\
\text { Difference }\end{array}$} & & & \\
\hline & & & & & Lower & Upper & & & \\
\hline Pair 1 & $\begin{array}{l}\mathrm{SME}(\text { estb. }>5 \text { years })- \\
\mathrm{SME}(\text { estb. }<5 \text { years }) \\
\text { years)following <50\% } \\
\text { processes }\end{array}$ & -3.818 & .874 & .263 & -4.405 & -3.231 & -14.491 & 10 & .000 \\
\hline Pair 2 & $\begin{array}{l}\text { SME(estb.> } 5 \text { years) - } \\
\text { SME(estb.<5 years) } \\
\text { following } 50-70 \% \\
\text { processes }\end{array}$ & -6.273 & 2.149 & .648 & -7.716 & -4.829 & -9.681 & 10 & .000 \\
\hline Pair 3 & $\begin{array}{l}\text { SME(estb. }>5 \text { years) - } \\
\text { SME(estb. }<5 \text { years) } \\
\text { following } 71-90 \% \\
\text { processes }\end{array}$ & 8.545 & 1.753 & .529 & 7.368 & 9.723 & 16.168 & 10 & .000 \\
\hline Pair 4 & $\begin{array}{l}\text { SME(estb. }>5 \text { years) - } \\
\text { SME(estb. }<5 \text { years) } \\
\text { following }>90 \% \text { processes }\end{array}$ & 2.182 & 1.328 & .400 & 1.290 & 3.074 & 5.449 & 10 & .000 \\
\hline
\end{tabular}

Pair 1, Pair 2, Pair 3, and Pair 4 show that there is a significant difference between the specific practices followed in SMEs (estb. $>5$ years) and SMEs (estb. $<5$ years) as calculated t value (sig. 2 tailed) is less than 0.05 . Here we can conclude from the consistent results of table 12 and table 13 that only 53\% of the specific practices are followed by SMEs established less than 5 years whereas $87 \%$ of the SPs of respective PAs of CMMI level 3.

\section{$5 \quad$ Results and Discussions}

In the present study, we have calculated the average of the percentage response got for SPs followed for CMMI Level-II and CMMI Level-III processes. If the SME follows SPs for particular CMMI Level process but these are less than 50\% of SPs then the response has been counted for <50\% SP. Similarly, 50\% to $70 \%, 71 \%$ to $90 \%$ and $>90 \%$ SPs blocks are created as shown in Table 12. The blocks are intentionally created in such a way that Maturity Levels could easily be identified according to Rule ML. Those SMEs are a candidate to be counted for ML who follows at least $70 \%$ of the SPs in particular process. SMEs lying in $<50 \%$ cannot be considered. As per the RULE ML, considering HIGH Zone or block $71 \%$ to $90 \%$ SPs and VERY HIGH Zone or block i.e. $>90 \%$ SPs together, more and more SMEs i.e. at least $70 \%$ SMEs should lie in this region. This condition is taken into consideration in Table 14.

Table 14 Percentage of CMMI PA-SPs followed by SMEs

\begin{tabular}{|l|l|l|r|r|r|r|r|r|}
\hline \multirow{2}{*}{$\begin{array}{l}\text { Maturity Level vs Time of } \\
\text { Establishment }\end{array}$} & \multicolumn{2}{|c|}{$<50 \%$ SPs } & \multicolumn{1}{|c|}{$50 \%-70 \%$ SPs } & \multicolumn{1}{c|}{$71 \%-90 \%$ SPs } & \multicolumn{2}{c|}{$>90 \%$ SPs } \\
\cline { 2 - 9 } & $\begin{array}{l}\text { SME } \\
\text { (Estb. }> \\
\text { 5yrs) }\end{array}$ & $\begin{array}{l}\text { SME } \\
\text { (Estb. } \\
\text { 5yrs) }\end{array}$ & $\begin{array}{l}\text { SME } \\
\text { (Estb. }> \\
\text { 5yrs) }\end{array}$ & $\begin{array}{l}\text { SME } \\
\text { (Estb. }< \\
5 y r s)\end{array}$ & $\begin{array}{l}\text { SME } \\
\text { (Estb. } \\
>5 y r s)\end{array}$ & $\begin{array}{l}\text { SME } \\
\text { (Estb. }< \\
5 y r s)\end{array}$ & $\begin{array}{l}\text { SME } \\
\text { (Estb. }> \\
5 y r s)\end{array}$ & $\begin{array}{l}\text { SME } \\
\text { (Estb. } \\
<5 y r s)\end{array}$ \\
\hline CMMI Level-II & 1.5 & 6.8 & 10.5 & 42.7 & 14.2 & 14.4 & 76.1 & 57.4 \\
\hline CMMI Level -III & 5 & 32.5 & 6.9 & 28.2 & 76.8 & 53 & 13.3 & 5.2 \\
\hline
\end{tabular}

Figure 2 shows the Average Percentage of SMEs following SPs for CMMI Level-II and CMMI Level-III with respect to year of establishment of SMEs i.e. less than or greater than 5 years.

Here, we can easily make out that SMEs (Estb. >5 years) have lesser intensity in $<50 \%$ and $50 \%-70 \%$ region. For CMMI Level-II, it is showing on an average $76 \%$ of the SMEs (Estb. >5 years) have accepted and followed greater than 
90\% of the SPs in CMMI Level-II processes. According to the 70\% rule, SMEs (Estb. >5 years) undoubtedly fall in CMMI Level-II.

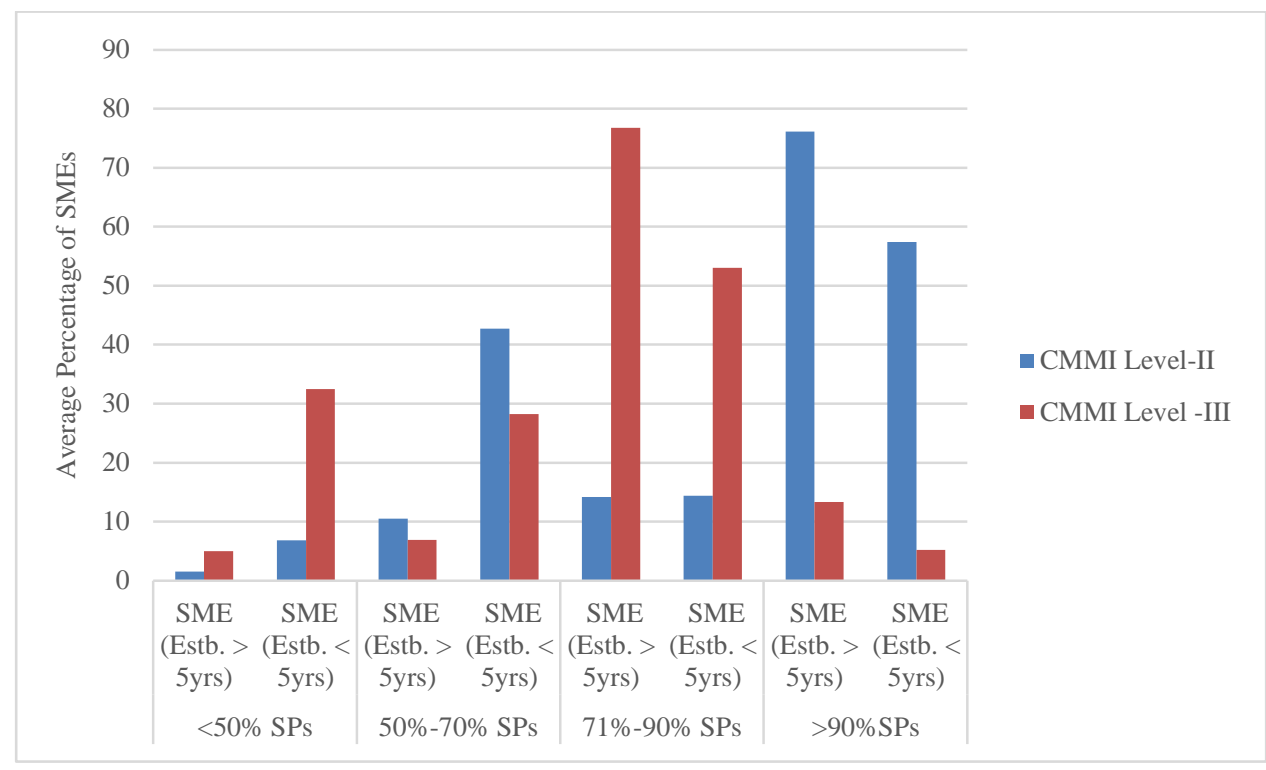

Figure 2 Average Percentage of SMEs following SPs for CMMI Level-II and CMMI Level-III with respect to Year of Establishment

SMEs (Estb. $<5$ years) reach up to 57\% in following >90\% of the SPs in CMMI Level-II. $14 \%$ of SMEs followed SPs in $70 \%-90 \%$. It clearly indicates on summing up 70-90 and above 90 block that $71 \%$ of the SMEs (Estb. $<5$ years) follow greater than $70 \%$ of the SPs of CMMI Level-II. According to the RULE ML, SMEs (Estb. $<5$ years) also fulfill the $70 \%$ rule. It can further be noted that $40 \%$ of the SMEs (Estb < 5yrs) lie in 50\% -70\%. It is shown in Table 14.

\subsection{Final Decision on assignment of Maturity Rating to Non-CMMI SMEs}

For assigning maturity rating informally i.e. without actual CMMI certification, we have worked according to the Criterion I and RULE ML. Accordingly, Happy face :) has been used to indicate 70\% Rule i.e. RULE ML fulfilled and sad face indicates the case if 70\% Rule i.e. RULE ML not fulfilled. It has been depicted in Table 15 and related findings have been discussed in the Section 6.1.1. The goal of the whole research has been quoted in section 6.1.2 as the final decision on ML for non-CMMI SMEs.

$70 \%$ Rule or RULE ML Fulfilled- :-

70\% Rule or RULE ML Not Fulfilled - :

Table 15 Percentage of SMEs who passed RULE ML

\begin{tabular}{|l|c|c|}
\hline & SMEs \%age (Estb. > 5yrs) & SMEs \%age (Estb. < 5yrs) \\
SPs for CMMI Levels & $91 \odot$ & $71 \odot$ \\
\hline CMMI Level-II SPs & $88 \odot ;$ & $52 \odot$ \\
\hline CMMI Level-III SPs & & \\
\hline
\end{tabular}

\subsubsection{Findings}

(:) Approximately 91\% SMEs (Estb. >5 yrs) followed greater than 71\%-100\% SPs at CMMI Level-II.

():Approximately $71 \%$ SMEs (Estb. $<5$ yrs) followed greater than 71\%-100\% SPs at CMMI Level-II 
(-) Approximately 88\% SMEs (Estb. > 5 yrs) followed greater than 71\%-100\% SPs at CMMI Level-III

:Approximately 52\% SMEs (Estb. $<5$ yrs) followed greater than 71\%-100\% SPs at CMMI Level-III

\subsubsection{Final Decision:}

- $\quad$ SMEs (Estb. > 5 yrs) are at CMMI Level-III informally.

- SMEs (Estb. $<5$ yrs) are at CMMI Level-II informally.

\section{Conclusions}

This section discusses the uniqueness of the research work with its limitations and future scope.

\subsection{Summary}

The paper has been successful in its attempt to answer the laid research questions. It has made a commendable contribution by establishing the maturity rating unofficially on the basis of CMMI Dev v1.3 for non-CMMI SMEs i.e. SMEs which are not certified by CMMI-DEV v1.3 but follow its practices informally. It differs from existing work (Iqbal et al. (2016)) for the following reasons: 1) The time of establishment of SMEs was taken as an important parameter for ascertaining the CMMI maturity. 2) The present research work is important and different from others as there is no such existing study for Indian SME. It has also been made crystal clear that the time of establishment of SMEs has a significant role to play in gaining process maturity and related maturity rating. Important decisions have been taken on maturity rating according to the RULE ML which is shown with the help of Figure 3. Figure 3 concludes the process maturity of SMEs on the basis of the time of establishment. It has also shown that SMEs (Estb. > 5 yrs) have claimed CMMI Level-III rating whereas SMEs (Estb. $<5$ yrs) have claimed CMMI Level-II rating according to RULE ML or $70 \%$ rule. Above the demarcation line for $70 \%$ rule lie the SMEs who have CMMI Level-II or CMMI Level-III.

- SMEs (Estb $>5$ yrs) and SMEs (Estb $<5$ yrs) both have cleared the $70 \%$ Rule to be rated at CMMI Level-II.

- SMEs (Estb>5 yrs) have cleared the 70\% Rule to be rated at CMMI Level-III but SMEs (Estb. <5 yrs) have not cleared the $70 \%$ Rule to be ranked for CMMI Level-III.

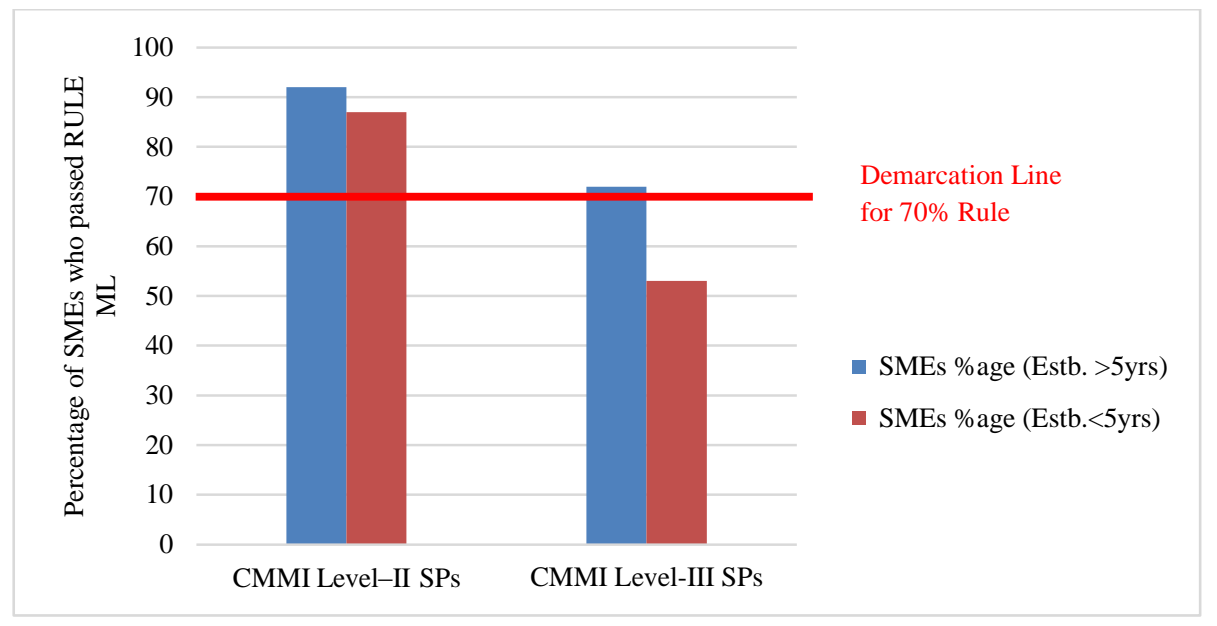

Figure 3: Average \%age of SMEs following more than 70\% of SPs for CMMI Level 2 and CMMI Level 3

It has been shown clearly that Non-CMMI SMEs (Estb. $>5$ yrs) are at CMMI Level-III and Non-CMMI SMEs (Estb. $<5$ yrs) are at CMMI Level-II. The appropriate authorities should focus on the SMEs that informally follow an adequate number of CMMI based SPI practices.

We have validated the responses statistically using $\mathrm{T}$ test, which is applied on the response set received. It showed that there is a significant difference in adoption percentages of practices followed in SMEs (Estb. more than 5 years) and 
SMEs (Estb. Less than 5 years) for CMMI Level 3. The same has been discussed in section 4.4.1 and 4.5.1. Table 12 and Table 13 presents T-Test for CMMI Level 2 and CMMI Level 3 respectively.

\subsection{Managerial Implications}

Indian software industry is an important sector for Gross Domestic Product (GDP) growth. So, periodic evaluation of the achieved maturity level by Non-CMMI SMEs is very crucial though unofficially. The informal or unofficial assignment of maturity rating to Non-CMMI SMEs represent the status of readiness of such SMEs for an official adoption of CMMI-DEV v1.3. The present study has answered many questions which previously remained unanswered regarding Indian software SMEs for a long time. This paper implies that Indian software SMEs have been following CMMI and accepted it though not officially but informally. These SMEs are continuously moving towards process improvisation and standardization. By achieving CMMI Level-III informally, Non-CMMI SMEs with more than five years of their establishment has suggested a positive move towards maturity. Indian software industry is no more immature. Indian software industry is progressing towards a new era. Time has been proved to be a crucial player in this scenario. SMEs (Estb.> 5 years) has moved to CMMI Level-III and present their candidature to achieve CMMI rating officially also. SMEs (Estb. $<5$ years) have achieved CMMI level-II informally and are able to work with the help of existing expertise in the Software Enterprise.

\subsection{Limitations of the research}

The present research work is limited in its attempt due to the following reasons:

- The sample of the study may not be representative of all the Indian regions. Demographically, Indian software industry is situated mostly in southern, central, northern and western parts of India. Only a few SMEs are located in the eastern part of India. So, the sample of this study does not cover the SEs from the eastern part of India.

- Internet era has emerged as a state-of-the-art information resource which can be used by SMEs for current SPI and CMMI-related needs. So, the present study has not concentrated upon official adoption of CMMI.

\subsection{Future Work}

- The present study is confined to southern, central, northern and western parts of India only. However, to corroborate and extend the outcomes of this study, an extensive research can be carried out with a larger sample covering different regions of the country.

- Since cultural, economic, social and demographic differences exist among the Small and Medium Scale Software organizations of different countries and regions, therefore, it would be interesting to find whether the findings of this study are appropriate for other countries also. Thus, a follow-up study can be undertaken with respect to other countries.

- The present study can also be automated for the RULE ML with more extensive data on SMEs. Non-CMMI SMEs data can be fed and RULE ML can be applied to establish the maturity rating on a larger set of SMEs.

\section{Acknowledgments}

We would like to thank the editor, area editor and anonymous reviewers for their valuable comments and suggestions to help and improve our research paper. We also thank the participating organizations who responded to the survey questionnaire and contributed significantly in the research.

\section{Appendix A}

Survey Questionnaire on Software Process Reengineering (SPR) is appended as a Supplemental Material in Appendix A

\section{References}

Alexandre, S., Renault, A. and Habra, N., (2006, August) 'OWPL: a gradual approach for 
software process improvement in SMEs', In 32nd EUROMICRO Conference on Software Engineering and Advanced Applications (EUROMICRO'06) (pp. 328-335).

Ali, R.Z.R.M. and Ibrahim, S. (2011) 'December. An application tool to support the implementation of integrated software process improvement for Malaysia's SME' In Software Engineering (MySEC), 2011 5th Malaysian Conference in (pp. 177-182).

Allen, Pat, Muthu Ramachandran, and Hisham Abushama. "PRISMS: an approach to software process improvement for small to medium enterprises." In Third International Conference on Quality Software, 2003. Proceedings., pp. 211-214. IEEE, 2003.

Andrews, James H., and Hanan L. Lutfiyya. "Experiences with a software maintenance project course." IEEE Transactions on Education 43, no. 4 (2000): 383-388.

Al-Tarawneh, M.Y., Abdullah, M.S. and Ali, A.B.M. (2011) 'A proposed methodology for establishing software process development improvement for small software development firms', Procedia Computer Science, Vol 3, pp.893-897.

Abushama, Hisham M. "PAM-SMEs: process assessment method for small to medium enterprises." Journal of Software: Evolution and Process 28, no. 8 (2016): 689-711.

Bibi, Stamatia, Ioannis Stamelos, George Gerolimos, and Vangelis Kollias. "BBN based approach for improving the software development process of an SME - a case study." Journal of Software Maintenance and Evolution: Research and Practice 22, no. 2 (2010).

Beecham, Sarah; Baddoo, Nathan; Hall, Tracy; Robinson, Hugh and Sharp, Helen (2008). Motivation in software engineering: a systematic literature review. Information and Software Technology, 50(9-10) pp. 860-878

Bessant, John, and Sarah Caffyn. "High-involvement innovation through continuous improvement." International Journal of Technology Management 14, no. 1 (1997): 7-28.

Berente, N. and Lee, J. (2014) 'How process improvement efforts can drive organisational innovativeness' Technology Analysis \& Strategic Management, Vol 26, No. 4, pp.417-433.

Birkinshaw, J., Hamel, G., \& Mol, M. J. (2008) 'Management Innovation', Academy of Management Review, Vol. 33, No.4, pp. 825-845.

Bahsoon, Rami, Ivan Mistrík, Nour Ali, T. S. Mohan, and Nenad Medvidović. "The future of software engineering IN and FOR the cloud." Journal of Systems and Software 86, no. 9 (2013): 2221-2224.

Bessant, John, and David Francis. "Developing strategic continuous improvement capability." International journal of operations \& production management 19, no. 11 (1999): 1106-1119.

Casale, Giuliano, Cristina Chesta, Peter Deussen, Elisabetta Di Nitto, Panagiotis Gouvas, Sotiris Koussouris, Vlado Stankovski et al. "Current and Future Challenges of Software Engineering for Services and Applications." In Cloud Forward, pp. 34-42. 2016.

Chapman, Ross, and Paul Hyland. "Strategy and continuous improvement in small-to-medium Australian manufacturers." Integrated Manufacturing Systems (2000).

Cohen, J. (1992). A power primer. Psychological Bulletin, 112, 155-159. Cohen, J. (1992). doi:10.1037/0033-2909.112.1.155

Cronbach LJ (1951). "Coefficient alpha and the internal structure of tests". Psychometrika. 16 (3): 297-334.

Dyba, T., (2003, September) 'Factors of software process improvement success in small and large organisations: an empirical study in the scandinavian context', In ACM SIGSOFT Software Engineering Notes, Vol. 28, No. 5, pp. 148-157. ACM

Garcia, I. and Pacheco, C. (2009) 'Toward automated support for software process improvement initiatives in small and medium size enterprises' In Software engineering research, management and applications 2009 (pp. 51-58). Springer Berlin Heidelberg. 


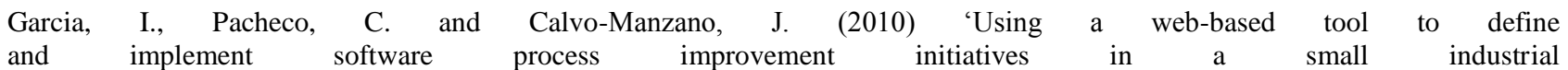
setting', IET software, Vol. 4, No. 4, pp.237-251.

Gill, Sukhpal Singh, Shreshth Tuli, Minxian Xu, Inderpreet Singh, Karan Vijay Singh, Dominic Lindsay, Shikhar Tuli et al. Transformative effects of IoT, Blockchain and artificial intelligence on cloud computing: evolution, vision, trends and open challenges. Internet of Things. 2019; 8:100118.

Garzás, Javier, and Mark C. Paulk. "A case study of software process improvement with CMMI-DEV and Scrum in Spanish companies." Journal of Software: Evolution and Process 25, no. 12 (2013): 1325-1333.

Garzás, Javier, and Mark C. Paulk. "A case study of software process improvement with CMMI-DEV and Scrum in Spanish companies." Journal of Software: Evolution and Process 25, no. 12 (2013): 1325-1333.

Hosalkar, A. and Bowonder, B. (2000) 'Software development management: critical success factors. International Journal of Technology Management', $V^{2}$ 19, No. 7-8, pp.760-772.

Iqbal, J., Ahmad, R. B., Nasir, M. H. N. M., Niazi, M., Shamshirband, S., \& Noor, M. A. (2016). Software SMEs' unofficial readiness for CMMI-based software process improvement. Software Quality Journal, 24(4), 997-1023.

Kish, L. (1995). Methods for design effects. Journal of official Statistics, 11(1), 55.

Khokhar, M.N., Zeshan, K. and Aamir, J. (2010, May) 'Literature review on the software process improvement factors in the small organisations' In New Trends in Information Science and Service Science (NISS), 2010 4th International Conference on (pp. 592-598).

Küpper, Steffen, Dietmar Pfahl, Kristjan Jürisoo, Philipp Diebold, Jürgen Münch, and Marco Kuhrmann. "How has SPI Changed in Times of Agile Development?-Results from a Multi-Method Study." (2019).

Kim, H. and Park, Y. (2010) 'The effects of open innovation activity on performance of SMEs: The case of Korea'. International Journal of Technology Management,Vol.52, No. (3/4), pp.236-256.

Lester, N. G., F. George Wilkie, Donald McFall, and M. P. Ware. "Investigating the role of CMMI with expanding company size for small-to medium-sized enterprises." Journal of Software Maintenance and Evolution: Research and Practice 22, no. 1 (2010): 17-31.

Munro,H.B. Statistical Methods for Health Care Research. Fifth Edition. Lippincott Williams \& Wilkins, Philadelphia, Baltimore, 2005.

Mishra, D. and Mishra, A. (2008, June) 'Software process improvement methodologies for small and medium enterprises' In International Conference on Product Focused Software Process Improvement (pp. 273-288). Springer Berlin Heidelberg.

Niazi, M., Ali Babar, M. and Katugampola, N.M. (2008) 'Demotivators of software process improvement: an empirical investigation', Software Process: Improvement and Practice, Vol. 13, No. 3, pp.249-264.

Nunnally, J. C. (1978). Assessment of Reliability. In: Psychometric Theory (2nd ed.). New York: McGraw-Hill. pages 245-246

O'Connor, R.V. and Coleman, G. (2009) 'Ignoring" Best Practice": Why Irish Software SMEs are Rejecting CMMI and ISO 9000', Australasian Journal of Information Systems, Vol. 16, No. 1. Pp. 7-30.

Pino, F.J., García, F. and Piattini, M. (2008) 'Software process improvement in small and medium software enterprises: a systematic review', Software Quality Journal, Vol. 16, No. 2, pp.237-261.

Pino, Francisco J., Oscar Pedreira, Félix García, Miguel Rodríguez Luaces, and Mario Piattini. "Using Scrum to guide the execution of software process improvement in small organizations." Journal of systems and software 83, no. 10 (2010): $1662-1677$. 
Rea ,M Louis and. Parker, Richard A (2014) Designing and Conducting Survey Research, Jossey-Bass (A WILEY PRODUCT); Fourth edition (2014)

Ramírez-Mora, Sandra L., Hanna Oktaba, and Juana Patlán Pérez. "Group maturity, team efficiency, and team effectiveness in software development: A case study in a CMMI-DEV Level 5 organization." Journal of Software: Evolution and Process (2019).

SEI, CMM Product Team (2006) 'CMMI for Development, Version $1.2^{\prime} \quad$ (CMU/SEI2006-TR-008, ADA455858), Pittsburgh, PA: Software Engineering Institute.

Singh, A and Aggarwal, H. (2017) 'Ruling out key enablers for software process reengineering in Indian small and medium enterprises' International Journal of Process Management and Benchmarking, Vol 7, No 4, pp.487-517.

Sharma, Pooja, and Amrit Lal Sangal. "Framework for empirical examination and modeling structural dependencies among inhibitors that impact SPI implementation initiatives in software SMEs." Journal of Software: Evolution and Process 30, no. 12 (2018): e1993.

Sharma, Pooja, and Amrit Lal Sangal. "Investigating the factors which impact SPI implementation initiatives in software SMEs-A systematic map and review." Journal of Software: Evolution and Process (2019): e2183.

Sukhpal Singh, Harinder Singh, "Case Study Based Software Engineering Project Development: State of Art”, International Journal of Scientific Research in Computer Science Applications and Management Studies, Vol. 2, No. 3, pp.1-15, 2013.

Sukhpal Singh, Rishideep Singh, "Reusability Framework for Cloud Computing", International Journal of Computational Engineering Research, Vol. 2 No. 6, pp. 169-177, 2012.

Sukhpal Singh, Inderveer Chana, "Introducing Agility in Cloud Based Software Development through ASD”, International Journal of u- and e- Service, Science and Technology, Vol.6, No.5, pp.191-202,2013.

Sukhpal Singh, Inderveer Chana (2012). Enabling Reusability in Agile Software Development. International Journal of Computer Applications, 50(13), 33-40.

Spadoni, G., Contini, S., \&Uguccioni, G. (2003) 'The new version of ARIPAR and the benefits given in assessing and managing major risks in industrialised areas', Process Safety and Environmental Protection, Vol. 81, No 1, pp. 19-30.

Sulayman, M. and Mendes, E. (2009, December) 'A systematic literature review of software process improvement in small and medium web companies' In International Conference on Advanced Software Engineering and Its Applications (pp. 1-8). Springer Berlin Heidelberg.

Sulayman, M., Urquhart, C., Mendes, E. and Seidel, S. (2012) 'Software process improvement success factors for small and medium Web companies: A qualitative study', Information and Software Technology, Vol. 54, No.5, pp.479-500.

Team, CP (2010) 'CMMI_ for development, version 1.3, improving processes for developing better products and services', No CMU/SEI-2010-TR-033. Boston: Software Engineering Institute.

Unterkalmsteiner, Michael, Tony Gorschek, AKM Moinul Islam, Chow Kian Cheng, Rahadian Bayu Permadi, and Robert Feldt. "A conceptual framework for SPI evaluation." Journal of Software: Evolution and Process 26, no. 2 (2014): 251-279.

Veldman, J. and Klingenberg, W. (2009) 'Applicability of the capability maturity model for engineer-to-order firms. International Journal of Technology Management', Vol. 48, No. 2, pp.219-239.

Wilkie, F. George, Donald McFall, and Fergal McCaffery. "An evaluation of CMMI process areas for small-to medium-sized software development organisations." Software Process: Improvement and Practice 10, no. 2 (2005): 189-201.

Wubben, E.F., Batterink, M., Kolympiris, $\quad$ C., $\quad$ Kemp, R.G. and Omta, O.S. (2015) 'Profiting from external knowledge: the impact of different external knowledge 


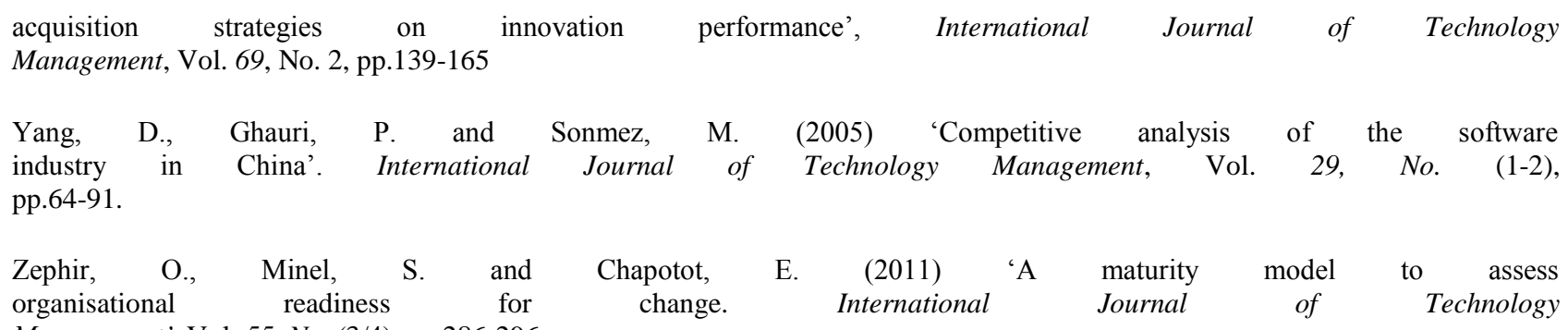

Management', Vol. 55, No. (3/4), pp.286-296.

Zhang, M., Hall, T., \& Baddoo, N. (2011). Code bad smells: a review of current knowledge. Journal of Software Maintenance and Evolution: research and practice, 23(3), 179-202. 


\section{Appendix A: Survey Questionnaire on Software Process Reengineering (SPR) Survey Cover Letter}

Software Development Manager/Senior Manager/Team Lead

Sub: Survey Questionnaire on Software Process Reengineering (SPR)

Dear Sir/Madam

We are doing research in Software Process Reengineering (SPR). The intent of the survey is to study existing software development processes and practices. The goal of the survey is to improvise the Software Process Reengineering (SPR) program or initiative according to industry's needs.

We would appreciate if you spare your valuable time for filling up the questionnaire. Filling the actual responses will prove to be of great help and support from your side. We hope that your responses would be true to the best of your knowledge. We assure you that the data collected will be used only for research purpose.

Here goes the link of Survey Questionnaire

https://docs.google.com/forms/d/e/1FAIpQLSfLCdN6uh3Rf3ApBRN4opG_y16VTr 8ou9kJGA2zybs_LCuLQ/viewform

If you have any queries about the survey questionnaire, please do not hesitate to contact us on at ashima@thapar.edu and s.s.gill@qmul.ac.uk

Thank you for your participation in advance.

Kind Regards

Ashima Singh and Sukhpal Singh Gill 


\section{CMMI Dev v1.3 based Questionnaire}

Time of Establishment of Software Organization

Refer Process Areas-Specific Practices in CMMI Dev v1.3 (KINDLY FIND IT BELOW THE QUESTIONAIRRE)

https://en.wikipedia.org/wiki/Process area (CMMI)\#Capacity and Availability Management .28C AM.29

Kindly rate the following Processes on the basis of Number of Specific Practices (SPs) adopted and followed in particular Process Areas in your software organization.
1- Don't Follow
2- $<\mathbf{5 0 \%}$
$3-50 \%-70 \%$
4- $71 \%-90 \%$
5- $<90 \%$

\begin{tabular}{|c|c|c|c|c|c|c|c|c|}
\hline Sno & Process Areas (PAs) & $\begin{array}{l}\text { Acronym } \\
\text { used for } \\
\text { PAs }\end{array}$ & $\begin{array}{l}\text { Specific } \\
\text { Practices } \\
\text { (SPs) }\end{array}$ & 1 & 2 & 3 & 4 & 5 \\
\hline 1 & Requirements Management & REQM & 5 & & & & & \\
\hline 2 & Project Planning & PP & 14 & & & & & \\
\hline 3 & Project Monitoring and Control & PMC & 10 & & & & & \\
\hline 4 & $\begin{array}{l}\text { Process and Product Quality } \\
\text { Assurance }\end{array}$ & PPQA & 4 & & & & & \\
\hline 5 & Configuration Management & $\mathrm{CM}$ & 7 & & & & & \\
\hline 6 & Measurement and Analysis & $\mathrm{MA}$ & 8 & & & & & \\
\hline 7 & Supplier Agreement Management & SAM & 6 & & & & & \\
\hline 8 & Decision Analysis and Resolution & DAR & 6 & & & & & \\
\hline 9 & Integrated Project Management & IPM & 7 & & & & & \\
\hline 10 & Organisational Process Definition & OPD & 7 & & & & & \\
\hline 11 & Organisational Process Focus & OPF & 9 & & & & & \\
\hline
\end{tabular}




\begin{tabular}{|c|l|l|l|l|l|l|l|l|}
\hline 12 & Organisational Training & OT & 7 & & & & & \\
\hline 13 & Product Integration & PI & 9 & & & & & \\
\hline 14 & Requirements Development & RD & 10 & & & & & \\
\hline 15 & Risk Management & RSKM & 7 & & & & & \\
\hline 16 & Technical Solution & TS & 6 & & & & & \\
\hline 17 & Validation & VAL & 5 & & & & & \\
\hline 18 & Verification & VER & 8 & & & & & \\
\hline 19 & Organisational Process Performance & OPP & 5 & & & & & \\
\hline 20 & Quantitative Project Management & QPM & 7 & & & & & \\
\hline 21 & Organisational Performance & OPM & 10 & & & & & \\
& Management & & & & & & & \\
\hline 22 & Causal Analysis and Resolution & CAR & 5 & & & & & \\
\hline
\end{tabular}

I certify that the information provided by me on the above form is true and correct to the best of my knowledge and belief.

\section{Capacity and Availability Management (CAM)}

- A Support process area at Maturity Level 3

\subsection{Purpose}

The purpose of Capacity and Availability Management (CAM) is to ensure effective service system performance and ensure that resources are provided and used effectively to support service requirements.

\subsection{Specific Practices by Goal}

- $\quad$ SG 1 Prepare for Capacity and Availability Management

- SP 1.1 Establish a Capacity and Availability Management Strategy

- SP 1.2 Select Measures and Analytic Techniques 
- SP 1.3 Establish Service System Representations

- $\quad$ SG 2 Monitor and Analyze Capacity and Availability

- $\quad$ SP 2.1 Monitor and Analyze Capacity

- SP 2.2 Monitor and Analyze Availability

- SP 2.3 Report Capacity and Availability Management Data

\section{Causal Analysis and Resolution (CAR)}

- A Support process area at Maturity Level 5

\subsection{Purpose}

The purpose of Causal Analysis and Resolution (CAR) is to identify causes of selected outcomes and take action to improve process performance.

\subsection{Specific Practices by Goal}

- SG 1 Determine Causes of Selected Outcomes

- SP 1.1 Select Outcomes for Analysis

- SP 1.2 Analyze Causes

- SG 2 Address Causes of Selected Outcomes

- SP 2.1 Implement Action Proposals

- SP 2.2 Evaluate the Effect of Implemented Actions

- SP 2.3 Record Causal Analysis Data

\section{Configuration Management (CM)}

- A Support process area at Maturity Level 2

\subsection{Purpose}

The purpose of Configuration Management (CM) is to establish and maintain the integrity of work products using configuration identification, configuration control, configuration status accounting, and configuration audits.

\subsection{Specific Practices by Goal}

- $\quad$ SG 1 Establish Baselines

- SP 1.1 Identify Configuration Items

- SP 1.2 Establish a Configuration Management System

- SP 1.3 Create or Release Baselines

- SG 2 Track and Control Changes

- $\quad$ SP 2.1 Track Change Requests

- SP 2.2 Control Configuration Items

- $\quad$ SG 3 Establish Integrity

- $\quad$ SP 3.1 Establish Configuration Management Records

- SP 3.2 Perform Configuration Audits

\section{Decision Analysis and Resolution (DAR)}

- A Support process area at Maturity Level 3 


\subsection{Purpose}

The purpose of Decision Analysis and Resolution (DAR) is to analyze possible decisions using a formal evaluation process that evaluates identified alternatives against established criteria.

\subsection{Specific Practices by Goal}

- $\quad$ SG 1 Evaluate Alternatives

- $\quad$ SP 1.1 Establish Guidelines for Decision Analysis

- SP 1.2 Establish EvaluationCriteria

- $\quad$ SP 1.3 Identify AlternativeSolutions

- $\quad$ SP 1.4 Select Evaluation Methods

- $\quad$ SP 1.5 Evaluate Alternative Solutions

- SP 1.6 Select Solutions

\section{Integrated Project Management (IPM)}

- A Project Management process area at Maturity Level 3

\subsection{Purpose}

The purpose of Integrated Project Management (IPM) is to establish and manage the project and the involvement of relevant stakeholders according to an integrated and defined process that is tailored from the organization's set of standard processes.

\subsection{Specific Practices by Goal}

- $\quad$ SG 1 Use the Project's Defined Process

- SP 1.1 Establish the Project's Defined Process

- SP 1.2 Use Organizational Process Assets for Planning Project Activities

- SP 1.3 Establish the Project's Work Environment

- $\quad$ SP 1.4 Integrate Plans

- SP 1.5 Manage the Project Using the Integrated Plans

- SP 1.6 Establish Teams

- SP 1.7 Contribute to Organizational Process Assets

- SG 2 Coordinate and Collaborate with Relevant Stakeholders

- SP 2.1 Manage Stakeholder Involvement

- SP 2.2 Manage Dependencies

- SP 2.3 Resolve Coordination Issues

\section{Measurement and Analysis (MA)}

- A Support process area at Maturity Level 2

\subsection{Purpose}

The purpose of Measurement and Analysis (MA) is to develop and sustain a measurement capability used to support management information needs.

\subsection{Specific Practices by Goal}


- SG 1 Align Measurement and AnalysisActivities

- $\quad$ SP 1.1 Establish Measurement

$$
\text { Objectives }
$$

- Resources,People,Facilities and Techniques.

- SP 1.2 Specify Measures

- Information Needs Document,Guidance,Reference and Reporting.

- SP 1.3 Specify Data Collection and Storage Procedures

- Sources,Methods,Frequency and Owners.

- $\quad$ SP 1.4 Specify Analysis Procedures

- Rules,Alarms,SPC and Variance.

- SG 2 Provide Measurement Results

- SP 2.1 Obtain Measurement Data

- Actual,Plan,Automatic and Manual.

- SP 2.2 Analyze Measurement Data

- Evaluate,Drill

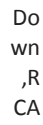

- SP 2.3 Store Data

$$
\text { and }
$$

Results

- Store,Secure,Accessible,History and Evidence.

- SP 2.4 Communicate Results

- Information Sharing,Dash Boards, Up to Date,Simple and Interpret.

\section{Organizational Process Definition (OPD)}

- A Process Management process area at Maturity Level 3

\subsection{Purpose}

The purpose of Organizational Process Definition (OPD) is to establish and maintain a usable set of organizational process assets, work environment standards, and rules and guidelines for teams.

\subsection{Specific Practices by Goal}

- $\quad$ SG 1 Establish Organizational Process Assets

- SP 1.1 Establish Standard Processes

- SP 1.2 Establish Lifecycle Model Descriptions

- SP 1.3 Establish Tailoring Criteria and Guidelines

- SP 1.4 Establish the Organization's Measurement Repository

- SP 1.5 Establish the Organization's Process Asset Library

- SP 1.6 Establish Work Environment Standards

- SP 1.7 Establish Rules and Guidelines for Teams

\section{Organizational Process Focus (OPF)}

- A Process Management process area at Maturity Level 3 


\subsection{Purpose}

The purpose of Organizational Process Focus (OPF) is to plan, implement, and deploy organizational process improvements based on a thorough understanding of current strengths and weaknesses of the organization's processes and process assets.

\subsection{Specific Practices by Goal}

- $\quad$ SG 1 Determine Process ImprovementOpportunities

- SP 1.1 Establish Organizational

$$
\text { ProcessNeeds }
$$

- SP 1.2 Appraise theOrganization's Processes

- SP 1.3 Identify the Organization's Process Improvements

- SG 2 Plan and Implement Process Improvements

- SP 2.1 Establish Process Action Plans

- $\quad$ SP 2.2 Implement Process Action Plans

- $\quad$ SG 3 Deploy Organizational Process Assets and Incorporate Experiences

- SP 3.1 Deploy Organizational Process Assets

- SP 3.2 Deploy StandardProcesses

- SP 3.3 Monitor the Implementation

- SP 3.4 Incorporate Experiences into Organizational Process Assets

\section{Organizational Performance Management (OPM) / Organizational Innovation and Deployment}

- A Process Management process area at Maturity Level 5

\subsection{Purpose}

The purpose of Organizational Performance Management (OPM) is to proactively manage the organization's performance to meet its business objectives.

\subsection{Specific Practices by Goal}

- $\quad$ SG 1 Manage Business Performance

- SP 1.1 Maintain Business Objectives

- SP 1.2 Analyze Process Performance Data

- SP 1.3 Identify Potential Areas for Improvement

- SG 2 Select Improvements

- SP 2.1 Elicit Suggested Improvements

- SP 2.2 Analyze Suggested Improvements

- SP 2.3 Validate Improvements

- SP 2.4 Select and Implement Improvements for Deployment

- $\quad$ SG 3 Deploy Improvements

- $\quad$ SP 3.1 Plan the Deployment

- SP 3.2 Manage the Deployment

- SP 3.3 Evaluate Improvement Effects

\section{Organizational Process Performance (OPP)}

\footnotetext{
- A Process Management process area at Maturity Level 4
} 


\subsection{Purpose}

The purpose of Organizational Process Performance (OPP) is to establish and maintain a quantitative understanding of the performance of selected processes in the organization's set of standard processes in support of achieving quality and process performance objectives, and to provide process performance data, baselines, and models to quantitatively manage the organization's projects.

\subsection{Specific Practices by Goal}

- SG 1 Establish Performance Baselines and Models

- SP 1.1 Establish Quality and Process Performance Objectives

- SP 1.2 Select Processes

- SP 1.3 Establish Process Performance Measures

- SP 1.4 Analyze Process Performance and Establish Process Performance Baselines

- SP 1.5 Establish Process Performance Models

\section{Organizational Training (OT)}

- A Process Management process area at Maturity Level 3

\subsection{Purpose}

The purpose of Organizational Training (OT) is to develop skills and knowledge of people so they can perform their roles effectively and efficiently.

\subsection{Specific Practices by Goal}

- $\quad$ SG 1 Establish an Organizational Training Capability

- SP 1.1 Establish Strategic Training Needs

- SP 1.2 Determine Which Training Needs Are the Responsibility of the Organization

- SP 1.3 Establish an Organizational Training Tactical Plan

- $\quad$ SP 1.4 Establish a Training Capability

- $\quad$ SG 2 Provide Training

- $\quad$ SP 2.1 Deliver Training

- SP 2.2 Establish Training Records

- SP 2.3 Assess Training Effectiveness

\section{Product Integration (PI)}

- An Engineering process area at Maturity Level 3

\subsection{Purpose}

The purpose of Product Integration (PI) is to assemble the product from the product components, ensure that the product, as integrated, behaves properly (i.e., possesses the required functionality and quality attributes), and deliver the product.

\subsection{Specific Practices by Goal}

- SG 1 Prepare for Product Integration 
- SP 1.1 Establish an Integration Strategy

- SP 1.2 Establish the Product Integration Environment

- SP 1.3 Establish Product Integration Procedures and Criteria

- $\quad$ SG 2 Ensure Interface Compatibility

- SP 2.1 Review Interface Descriptions for Completeness

- SP 2.2 Manage Interfaces

- SG 3 Assemble Product Components and Deliver the Product

- SP 3.1 Confirm Readiness of Product Components for Integration

- SP 3.2 Assemble Product Components

- SP 3.3 Evaluate Assembled Product Components

- SP 3.4 Package and Deliver the Product or Product Component

\section{Project Monitoring and Control (PMC)}

- A Project Management process area at Maturity Level 2

\subsection{Purpose}

The purpose of Project Monitoring and Control (PMC) is to provide an understanding of the project's progress so that appropriate corrective actions can be taken when the project's performance deviates significantly from the plan.

\subsection{Specific Practices by Goal}

- SG 1 Monitor the Project Against the Plan

- SP 1.1 Monitor Project Planning Parameters

- SP 1.2 Monitor Commitments

- SP 1.3 Monitor Project Risks

- SP 1.4 Monitor Data Management

- SP 1.5 Monitor Stakeholder Involvement

- SP 1.6 Conduct

Progress

Reviews

- SP 1.7 Conduct

Milestone

Reviews

- $\quad$ SG 2 Manage Corrective Action to Closure

- SP 2.1 Analyze Issues

- SP 2.2 Take Corrective Action

- SP 2.3 Manage Corrective Actions

\section{Project Planning (PP)}

- A Project Management process area at Maturity Level 2

\subsection{Purpose}

The purpose of Project Planning (PP) is to establish and maintain plans that define project activities.

14.2. Specific Practices by Goal

- SG 1 Establish Estimates 
- SP 1.1 Estimate the Scope of the Project

- SP 1.2 Establish Estimates of Work Product and Task Attributes

- SP 1.3 Define Project Lifecycle Phases

- $\quad$ SP 1.4 Estimate Effort and Cost

- SG 2 Develop a Project Plan

- $\quad$ SP 2.1 Establish the Budget and Schedule

- SP 2.2 Identify Project Risks

- SP 2.3 Plan Data Management

- SP 2.4 Plan the Project's Resources

- SP 2.5 Plan Needed Knowledge and Skills

- SP 2.6 Plan Stakeholder Involvement

- SP 2.7 Establish the Project Plan

- SG 3 Obtain Commitment to the Plan

- SP 3.1 Review Plans that Affect the Project

- SP 3.2 Reconcile Work and Resource Levels

- SP 3.3 Obtain Plan Commitment

\section{Process and Product Quality Assurance (PPQA)}

- A Support process area at Maturity Level 2

\subsection{Purpose}

The purpose of Process and Product Quality Assurance (PPQA) is to provide staff and management with objective insight into processes and associated work products.

\subsection{Specific Practices by Goal}

- SG 1 Objectively Evaluate Processes and Work Products

- SP 1.1 Objectively Evaluate Processes

- SP 1.2 Objectively Evaluate Work Products

- $\quad$ SG 2 Provide Objective Insight

- SP 2.1 Communicate and Resolve Noncompliance Issues

- SP 2.2 Establish Records.

\section{Quantitative Project Management (QPM)}

- A Project Management process area at Maturity Level 4

\subsection{Purpose}

The purpose of the Quantitative Project Management (QPM) process area is to quantitatively manage the project to achieve the project's established quality and process performance objectives.

- SG 1 Prepare for Quantitative Management

- $\quad$ SP 1.1 Establish the Project's Objectives

- SP 1.2 Compose the DefinedProcesses

- $\quad$ SP 1.3 Select Subprocesses and Attributes

- SP 1.4 Select Measures and Analytic Techniques

- SG 2 Quantitatively Manage the Project

- SP 2.1 Monitor the Performance of Selected Subprocesses

- SP 2.2 Manage Project Performance

- SP 2.3 Perform Root CauseAnalysis 


\section{Requirements Development (RD)}

- An Engineering process area at Maturity Level 3.

17.1. Purpose

The purpose of Requirements Development (RD) is to elicit, analyze, and establish customer, product, and product component requirements.

17.2. Specific Practices by Goal

- SG 1 Develop Customer Requirements

- $\quad$ SP 1.1 Elicit Needs

- SP 1.2 Transform Stakeholder Needs into Customer Requirements

- SG 2 Develop Product Requirements

- SP 2.1 Establish Product and Product Component Requirements

- SP 2.2 Allocate Product Component Requirements

- SP 2.3 Identify Interface Requirements

- $\quad$ SG 3 Analyze and Validate Requirements

- SP 3.1 Establish Operational Concepts and Scenarios

- SP 3.2 Establish a Definition of Required Functionality and Quality Attributes

- SP 3.3 Analyze Requirements

- SP 3.4 Analyze Requirements to Achieve Balance

- SP 3.5 Validate Requirements

\section{Requirements Management (REQM)}

- A Project Management process area at Maturity Level 2

\subsection{Purpose}

The purpose of Requirements Management (REQM) is to manage requirements of the project's products and product components and to ensure alignment between those requirements and the project's plans and work products.

18.2. Specific Practices by Goal

- $\quad$ SG 1 Manage Requirements

- SP 1.1 Understand Requirements

- SP 1.2 Obtain Commitment to Requirements

- SP 1.3 Manage Requirements Changes

- SP 1.4 Maintain Bidirectional Traceability of Requirements

- SP 1.5 Ensure Alignment Between Project Work and Requirements

\section{Risk Management (RSKM)}

- A Project Management process area at Maturity Level 3 


\subsection{Purpose}

The purpose of Risk Management (RSKM) is to identify potential problems before they occur so that risk handling activities can be planned and invoked as needed across the life of the product or project to mitigate adverse impacts on achieving objectives.

- $\quad$ SG 1 Prepare for Risk Management

- $\quad$ SP 1.1 Determine Risk Sources and Categories

- SP 1.2 Define Risk Parameters

- SP 1.3 Establish a Risk Management Strategy

- $\quad$ SG 2 Identify and Analyze Risks

- SP 2.1 Identify Risks

- SP 2.2 Evaluate, Categorize, and Prioritize Risks

- $\quad$ SG 3 Mitigate Risks

- SP 3.1 Develop Risk Mitigation Plans

- SP 3.2 Implement Risk Mitigation Plans

\section{Supplier Agreement Management (SAM)}

- A Project Management process area at Maturity Level 2

\subsection{Purpose}

The purpose of Supplier Agreement Management (SAM) is to manage the acquisition of products from suppliers.

\subsection{Specific Practices by Goal}

- $\quad$ SG 1 Establish Supplier Agreements

- SP 1.1 Determine Acquisition Type

- $\quad$ SP 1.2 Select Suppliers

- SP 1.3 Establish Supplier Agreements

- $\quad$ SG 2 Satisfy Supplier Agreements

- SP 2.1 Execute the Supplier Agreement

- SP 2.2 Accept the Acquired Product

- SP 2.3 Ensure Transition of Products

\section{Technical Solution (TS)}

- An Engineering process area at Maturity Level 3

\subsection{Purpose}

The purpose of Technical Solution (TS) is to select design and implement solutions to requirements. Solutions, designs, and implementations encompass products, product components, and product related lifecycle processes either singly or in combination as appropriate.

\subsection{Specific Practices by Goal}

- $\quad$ SG 1 Select Product Component Solutions

- SP 1.1 Develop Alternative Solutions and Selection Criteria

- SP 1.2 Select Product Component Solutions

- $\quad$ SG 2 Develop the Design

- SP 2.1 Design the Product or Product Component 
- SP 2.2 Establish a Technical Data Package

- $\quad$ SP 2.3 Design Interfaces Using Criteria

- SP 2.4 Perform Make, Buy or Reuse Analyses

- SG 3 Implement the Product Design

- SP 3.1 Imple ment

the Design

- SP 3.2 Develop Product Support Documentation

\section{Validation (VAL)}

- An Engineering process area at Maturity Level 3

\subsection{Purpose}

The purpose of Validation (VAL) is to demonstrate that a product or product component fulfills its intended use when placed in its intended environment.

- SG 1 Prepare for Validation

- SP 1.1 Select Products for Validation

- SP 1.2 Establish the Validation Environment

- SP 1.3 Establish Validation Procedures and Criteria

- SG 2 Validate Product or Product Components

- SP 2.1 Perform Validation

- SP 2.2 Analyze Validation Results

\section{Verification (VER)}

- An Engineering process area at Maturity Level 3

\subsection{Purpose}

The purpose of Verification (VER) is to ensure that selected work products meet their specified requirements.

\subsection{Specific Practices by Goal}

- $\quad$ SG 1 Prepare for Verification

- SP 1.1 Select Work Products for Verification

- SP 1.2 Establish the Verification Environment

- SP 1.3 Establish Verification Procedures and Criteria

- $\quad$ SG 2 Perform Peer Reviews

- $\quad$ SP 2.1 Prepare for Peer Reviews

- SP 2.2 Conduct Peer Reviews

- $\quad$ SP 2.3 Analyze Peer Review Data

- $\quad$ SG 3 Verify Selected Work Products

- SP 3.1 Perform Verification

- SP 3.2 Analyze Verification Results 